\title{
A Study of Control Methodologies for the Trade-Off between Battery Aging and Energy Consumption on Electric Vehicles with Hybrid Energy Storage Systems
}

\author{
Kevin Mallon*(D) and Francis Assadian (D) \\ Department of Mechanical and Aerospace Engineering, University of California, Davis, CA 95616, USA; \\ fassadian@ucdavis.edu \\ * Correspondence: krmallon@ucdavis.edu
}

check for

updates

Citation: Mallon, K.; Assadian, F.

A Study of Control Methodologies for the Trade-Off between Battery Aging and Energy Consumption on Electric Vehicles with Hybrid Energy Storage Systems. Energies 2022, 15, 600.

https://doi.org/10.3390/en15020600

Academic Editor: Daniel-Ioan Stroe

Received: 30 November 2021

Accepted: 11 January 2022

Published: 14 January 2022

Publisher's Note: MDPI stays neutral with regard to jurisdictional claims in published maps and institutional affiliations.

Copyright: (C) 2022 by the authors. Licensee MDPI, Basel, Switzerland. This article is an open access article distributed under the terms and conditions of the Creative Commons Attribution (CC BY) license (https:// creativecommons.org/licenses/by/ $4.0 /)$.

\begin{abstract}
Hybrid and electric vehicle batteries deteriorate from use due to irreversible internal chemical and mechanical changes, resulting in decreased capacity and efficiency of the energy storage system. This article investigates the modeling and control of a lithium-ion battery and ultracapacitor hybrid energy storage system for an electric vehicle for improved battery lifespan and energy consumption. By developing a control-oriented aging model for the energy storage components and integrating the aging models into an energy management system, the trade-off between battery degradation and energy consumption can be minimized. This article produces an optimal aging-aware energy management strategy that controls both battery and ultracapacitor aging and compares these results to strategies that control only battery aging, strategies that control battery aging factors but not aging itself, and non-optimal benchmark strategies. A case study on an electric bus with variously-sized hybrid energy storage systems shows that a strategy designed to control battery aging, ultracapacitor aging, and energy losses simultaneously can achieve a $28.2 \%$ increase to battery lifespan while requiring only a 7.0\% decrease in fuel economy.
\end{abstract}

Keywords: electric vehicle; hybrid vehicle; energy management; lithium ion; ultracapacitor; battery aging

\section{Introduction}

Due to their low operating speeds and frequent stopping and starting, buses are a prime candidate for hybridization or electrification in the goal of reducing transportation sector emissions. The stop-and-go behavior, in particular, means that regenerative braking can recover a large portion of expended power. However, for handling bus loads and ranges, the lithium ion batteries needed for electric vehicles (EVs) and hybrid-electric vehicles (HEVs) can be prohibitively expensive and heavy [1]. Additionally, the large current spikes from acceleration and deceleration can degrade the battery, reducing range, increasing energy consumption [2,3], and, in general, adding new operational costs to such vehicles.

One possible solution to this is to use a Hybrid Energy Storage System (HESS) - a combination of lithium ion energy storage with an ultracapacitor (UC) sized to handle large charge and discharge currents-in place of standard battery energy storage. In general, lithium ion batteries have a high energy density but low power density: they can store a large amount of charge, but cannot access it quickly without degrading. Specifically, large currents to and from the battery cause its capacity to fade and internal resistance to grow. High temperatures and deep discharges also contribute to battery aging. On the contrary, ultracapacitors have a low energy density and high power density [4]. A HESS, then, allows one to obtain the efficient storage of lithium batteries while allowing an ultracapacitor to handle the large currents [4,5]. The aging of UCs does not depend on 
current magnitude or discharge depth, rather on time, temperature, and cell voltage [6-8]; therefore, there is not necessarily a tradeoff between battery aging and UC aging in HESSs.

Current research on HESSs considers HEV, EV, and fuel cell vehicle applications. The bulk of the literature, for instance [9-14], is concerned with the optimal sizing of the HESS so as to maximize the cost-effectiveness of such a system. However, battery aging is often not considered directly in this optimization; instead, battery aging factors such as high temperatures and currents are minimized, rather than battery aging directly, and the benefits to overall aging are only assumed [14]. Some related works that does directly address aging are described here. In reference [15], for instance, an optimal control policy is developed to control UC behavior. This policy demonstrated clear aging improvements over an uncontrolled system using passive energy management. Reference [16] used multi-objective optimization while directly incorporating an aging model and using a rule-based control system to govern energy management for a study on HESS sizing in EVs. Reference [17], likewise, carried out a parametric study on battery degradation versus UC size in EVs, using a control system based on fuzzy logic. Reference [18] considered a HESS that used lead-acid batteries rather than lithium ion, and developed an HEV energy management strategy that tuned for battery life extension. Notably, they found that, for the HESS to be cost-effective, a $50 \%$ increase in battery cycle life was required. Reference [19] compared the aging benefits of an optimally-sized HESS to the theoretical maximum benefits-battery aging reductions with an infinitely large HESS. These benefits were experimentally verified, with the developed approach decreasing battery power fade and temperature rise in lithium-ion batteries on a vehicle load profile. Most notably, references [20-22] demonstrate an optimal control strategy to directly minimize battery aging in a HESS for a plug-in HEV.

However, the literature is lacking in direct aging control for EVs, in the impact of ultracapacitor aging in the HESS, and in methods to assess the economic benefit of the HESS given UC aging. Although studies on direct aging control for HEVs do exist, for instance $[2,3,23,24]$, EVs pose a unique control problem due to the fewer controlled variables and different component sizes. This research fills these gaps in knowledge: new energy management strategies to control battery aging and to jointly control battery aging, ultracapacitor aging, and energy losses are developed and compared to existing methods. Then, the cost/benefit analysis of a HESS that considers ultracapacitor aging is performed, and the drawbacks of overusing the ultracapacitor are discussed.

This paper begins by developing the aging models for an electric vehicle hybrid energy storage system, with an aside showing why there must necessarily be a trade-off between battery aging and energy consumption for this vehicle configuration. Next, energy management systems (EMS) for aging control are developed, including Deterministic Dynamic Programming (DDP), Stochastic Dynamic Programming (SDP), and Load-Leveling (LL). The vehicle model and aging-aware controllers are then applied to a case study of an electric bus with a HESS, simulated for the lifespan of the battery. Finally, these simulation results are analyzed, and conclusions are drawn regarding the benefits of optimal control and aging-aware control for vehicle energy management.

\section{Modeling}

This section develops a model for an electric vehicle with a hybrid energy storage system. Specifically, the model is of a HESS-equipped electric bus using lithium-ion batteries for energy storage and ultracapacitor modules for handling large currents, as depicted in Figures 1 and 2. The first subsection presents the overall vehicle model, including vehicle dynamics, motor efficiencies, battery dynamics, and so on. The next two subsections deal with the battery aging and ultracapacitor aging models. The final subsection discusses why, based on the provided models, aging control can have a negative impact on fuel economy. 


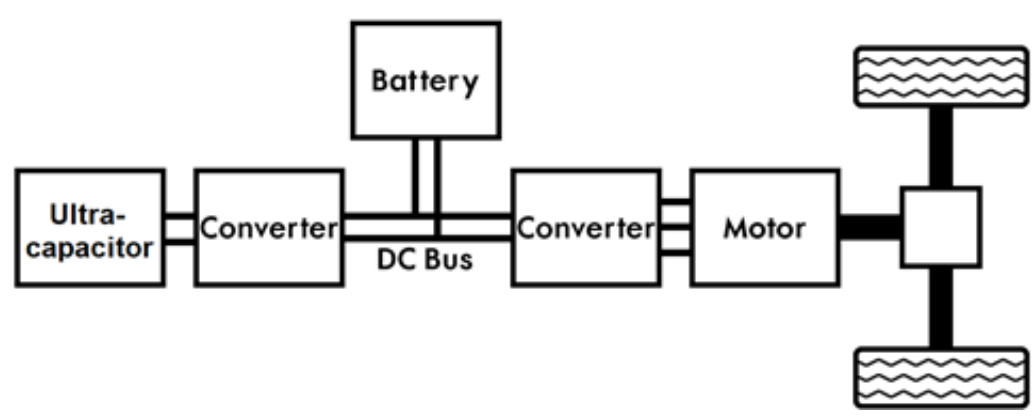

Figure 1. Powertrain of an EV with a UC.

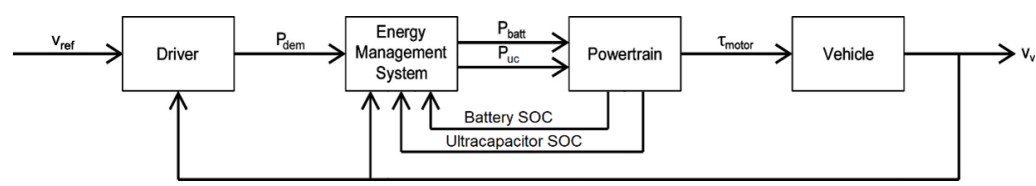

Figure 2. Block diagram for energy management of an EV with a UC.

\subsection{Vehicle Modeling}

\subsubsection{Vehicle Dynamics}

For this study, a backwards-facing quasi-static vehicle model [25] is used to represent the vehicle dynamics. In this model, it is assumed that the driver accurately follows the velocity of a given drive cycle, eliminating the need for a driver model and allowing the time-history of the electrical power demand to be calculated in advance.

This research uses a backwards-facing quasi-static vehicle model [25] to simulate the vehicle dynamics. This method assumes that the model accurately follows a specified velocity profile, which allows for calculating the acceleration and, therefore, the electrical power request can be computed in advance, eliminating the need for a driver model.

The vehicle body is affected by inertial forces, aerodynamic drag, and rolling resistance, while gravitational forces (such as those due to driving on inclines) are neglected. The drag force is given by

$$
F_{\text {drag }}=\frac{1}{2} \rho A_{f} C_{D}\left(v_{v}\right)^{2}
$$

where $\rho, A_{f}, C_{D}$, and $v_{v}$ are the air density, frontal area, drag coefficient, and vehicle velocity, respectively. Rolling resistance is given by

$$
F_{\text {roll }}=M_{v} g C_{R}
$$

where $M_{v}, g$, and $C_{R}$ are the vehicle's total mass (including components such as the engine and generator), acceleration due to gravity, and rolling resistance coefficient. In a backwards-facing model, the acceleration and the vehicle mass determine the inertial force on the vehicle as

$$
F_{\text {inertial }}=M_{e q} \frac{d v_{v}}{d t} .
$$

$M_{e q}$ is the combined bus mass and equivalent mass due to the rotational inertia of the motor and wheels

$$
M_{e q}=M_{v}+4 J_{w}\left(\frac{1}{R_{w}}\right)^{2}+J_{m}\left(\frac{N_{f d} N_{g b}}{R_{w}}\right)^{2}
$$

where $J_{w}, R_{w}, J_{m}, N_{f d}$, and $N_{g b}$ are the rotational inertia of a single wheel, the wheel radius, the rotational inertia of the motor, the final drive ratio, and the gearbox ratio for a single-speed gearbox, respectively. The acceleration term in (3) is approximated from a given velocity profile according to

$$
\frac{d v_{v}}{d t}(t) \approx \frac{v_{v}(t+\Delta t)-v_{v}(t-\Delta t)}{2 \Delta t} .
$$


These three forces sum together to give the tractive force on the bus.

$$
F_{\text {traction }}=F_{\text {inertial }}+F_{\text {drag }}+F_{\text {roll }}
$$

Parameter values for the vehicle model can be found in Table 1. The bus is assumed to be fully loaded and at its maximum allowable weight. The bus's physical parameters are based on the existing literature on bus simulation [26-28].

Table 1. Vehicle model physical parameters.

\begin{tabular}{ccc}
\hline Parameter & Variable & Value \\
\hline Vehicle Mass & $M_{\mathcal{v}}$ & $18,181 \mathrm{~kg}$ \\
Frontal Area & $A_{f}$ & $8.02 \mathrm{~m}^{2}$ \\
Drag Coefficient & $C_{D}$ & 0.55 \\
Roll Resistance Coefficient & $C_{R}$ & 0.008 \\
Wheel Inertia & $J_{w}$ & $20.52 \mathrm{~kg}-\mathrm{m}^{2}$ \\
Motor Inertia & $J_{m}$ & $0.277 \mathrm{~kg}-\mathrm{m}^{2}$ \\
Wheel Radius & $R_{w}$ & $0.48 \mathrm{~m}$ \\
Final Drive Ratio & $N_{f d}$ & $5.1: 1$ \\
Gearbox Ratio & $N_{g b}$ & $5: 1$ \\
Transmission Efficiency & $\eta_{\text {trans }}$ & $96 \%$ \\
\hline
\end{tabular}

\subsubsection{Transmission}

Next, the vehicle velocity and tractive force are equated to motor torque and angular velocity. The motor torque is given by

$$
\tau_{m}= \begin{cases}\left(\frac{R_{w}}{N_{f d} N_{g b}} F_{\text {traction }}\right) / \eta_{\text {trans }}, & F_{\text {traction }} \geq 0 \\ \left.\frac{R_{w}}{N_{f d} N_{g b}} F_{\text {traction }}\right) \cdot \eta_{\text {trans }}, & F_{\text {traction }}<0\end{cases}
$$

$\eta_{\text {trans }}$ is the transmission efficiency, represented as torque losses. The motor speed is then given by

$$
\omega_{m}=\frac{N_{f d} N_{g b}}{R_{w}} v_{v}
$$

The mechanical power $P_{\text {mech }}$ needed to drive the vehicle is expressed in terms of the above torque and angular velocity.

$$
P_{m e c h}=\tau_{m} \cdot \omega_{m}
$$

In this formulation, $P_{\text {mech }}$ is positive during acceleration. Parameter values for the transmission can be found in Table 1 .

\subsubsection{Motor and Power Electronics}

The motor torque and angular velocity are used to find the motor efficiency $\eta_{\text {motor }}$, which is constrained to $0<\eta_{\text {motor }}<1$. The motor efficiency is determined from a static efficiency map from the National Renewable Energy Laboratory's Advanced Vehicle Simulator (ADVISOR) data library [29]. This efficiency includes both the motor itself as well as the associated power electronics. The bus model in this research uses a $250 \mathrm{~kW} \mathrm{AC}$ induction motor.

Once the motor efficiency is found, it can be used to evaluate the driver's electrical power request, $P_{\text {req }}$.

$$
P_{\text {req }}= \begin{cases}P_{\text {mech }} / \eta_{\text {motor }} & \tau_{m} \geq 0 \\ P_{\text {mech }} \cdot \eta_{\text {motor }} & \tau_{m}<0\end{cases}
$$


The electrical power request is met with power from the battery $P_{b a t t}$ and ultracapacitor $P_{u c}$. Given that this is a backwards-facing simulation, the power request must always be met.

$$
P_{\text {req }}=P_{b a t t}+P_{u c}
$$

In later sections, the ultracapacitor power is developed as the energy management system's controlled variable. Then, $P_{b a t t}$ is dependent on $P_{r e q}$ and $P_{u c}$, and Equation (11) is rewritten as

$$
P_{b a t t}=P_{r e q}-P_{u c}
$$

\subsubsection{Battery}

The EV's lithium-ion battery cells are modeled with the simple equivalent circuit shown in Figure 3, where $V_{\text {cell }}$ is the single-cell open-circuit voltage (OCV) and $R_{\text {cell }}$ is the single-cell equivalent series resistance [4]. The individual cells are then combined into a larger battery pack. Only one state variable is required for this model, the state of charge (SOC). The OCV and internal resistance are variable parameters dependent on SOC. The formulas for these parameters are given in [30], which develops a lithium-iron-phosphate battery from experimental data.

\section{Battery Cell \\ Battery Pack}

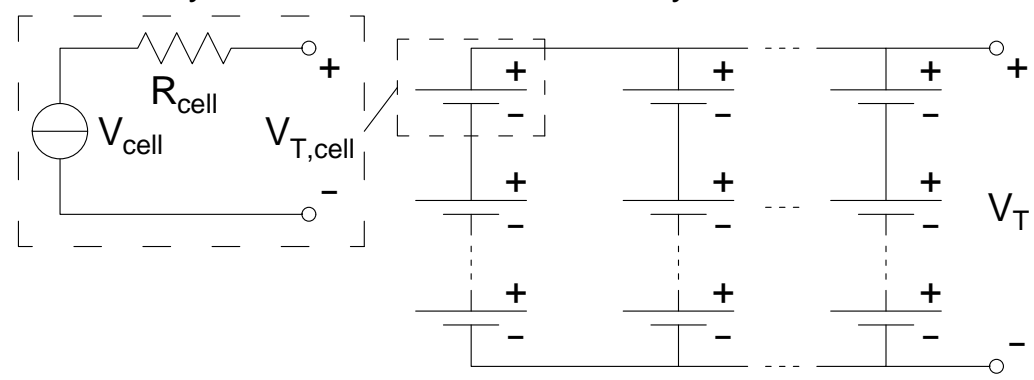

Figure 3. Battery pack equivalent circuit.

The battery pack equivalent resistance $R_{e q}$ is given by

$$
R_{e q}=R_{\text {cell }} \cdot \frac{N_{\text {ser }}}{N_{\text {par }}}
$$

where $N_{\text {ser }}$ and $N_{\text {par }}$ are the number of cells in series and in parallel, respectively. The battery pack OCV is likewise given by

$$
V_{\text {ocv }}=N_{\text {ser }} \cdot V_{\text {cell }}
$$

The battery pack's terminal voltage is found from the OCV and battery power $P_{b a t t}$ using the equivalent circuit in Figure 3.

$$
\begin{gathered}
I_{b a t t}=P_{b a t t} / V_{T} \\
V_{T}=V_{o c v}-I_{b a t t} \cdot R_{e q}
\end{gathered}
$$

Then, substituting the current equation into the voltage equation and solving yields

$$
\begin{gathered}
V_{T}^{2}=V_{o c v} \cdot V_{T}-P_{b a t t} \cdot R_{e q} \\
V_{T}=1 / 2\left(V_{o c v}+\sqrt{V_{o c v}^{2}-4 \cdot P_{b a t t} \cdot R_{e q}}\right)
\end{gathered}
$$


Substituting $V_{T}$ into Equation (15) allows the battery current to be found explicitly. Then, integrating the battery current yields the state of charge.

$$
\operatorname{SOC}(k+1)=\operatorname{SOC}(k)+\Delta t \cdot \frac{I_{\text {batt }}}{Q_{\text {batt }}},
$$

where $Q_{\text {batt }}$ is the battery pack's charge capacity in coulombs and $\Delta t$ is the integration time step.

The battery model parameters are given in Table 2. The number of cells in series ensures that the battery pack, the OCV, is in line with the requirements of [31]. The number of parallel cells was chosen so that the bus can meet the power requirements in $[31,32]$ to drive continuously on an urban bus velocity profile for four hours. Note that Table 2 only gives the nominal values for $R_{\text {cell }}$ and $V_{\text {cell }}$-in reality, these parameters vary with SOC and other operating conditions [30].

Table 2. Battery model parameters.

\begin{tabular}{ccc}
\hline Parameter & Variable & Value \\
\hline Battery Cells in Parallel & $N_{\text {par }}$ & 400 cells \\
Parallel Sets in Series & $N_{\text {ser }}$ & 100 sets \\
Total Charge Capacity & $Q_{b a t t}$ & $340 \mathrm{Ah}$ \\
Nominal Open Circuit Voltage & $V_{\text {cell }}$ & $3.8 \mathrm{v}$ \\
Nominal Equivalent Resistance & $R_{\text {cell }}$ & $7.5 \mathrm{~m} \Omega$ \\
\hline
\end{tabular}

\subsubsection{Ultracapacitor}

The ultracapacitor modules are modeled as the first-order equivalent circuit shown in Figure 4. The model itself is based on the 100F ultracapacitor model derived in [33]. Ultracapacitor model parameters are given in Table 3. The ultracapacitor pack, similar to the battery pack, consists of ultracapacitors arranged in $N_{p c}$ modules in a parallel set and $N_{s c}$ sets in series. The number of modules is variable so that the effectiveness and cost-benefit of the HESS can be considered across a range of designs.

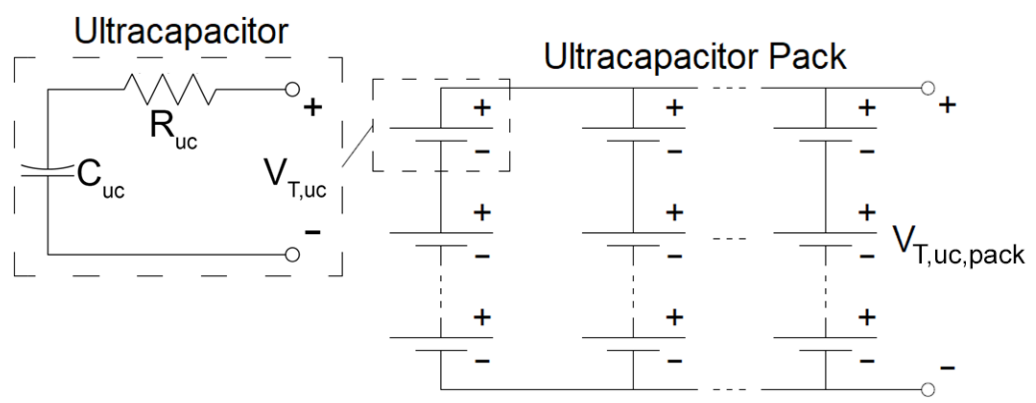

Figure 4. Ultracapacitor pack equivalent circuit.

Table 3. Ultracapacitor model parameters.

\begin{tabular}{ccc}
\hline Parameter & Variable & Value \\
\hline UC modules in Parallel & $N_{p c}$ & variable \\
UC Parallel Sets in Series & $N_{s c}$ & 100 sets \\
Resistance & $R_{u c}$ & $44.3 \mathrm{~m} \Omega$ \\
Capacitance & $C_{u c}$ & $105.9 \mathrm{~F}$ \\
\hline
\end{tabular}

The UC pack is connected to the DC bus through a converter, as shown in Figure 1. The converter allows the UC pack to operate independently of the DC bus voltage. The 
ultracapacitor pack power is indicated by $P_{u c}$, where $P_{u c}$ is positive while discharging and negative while charging. Then, each individual module has power $P_{u c, \text { module }}$ given by

$$
P_{u c, \text { module }}=\frac{P_{u c}}{N_{p c} N_{s c}}
$$

For capacitor charge $q_{u c}$ at some given power $P_{u c, \text { module }}$, the current and terminal voltage $I_{u c}$ and $V_{T, u c}$ are found similarly to Equations (15)-(18).

$$
\begin{gathered}
I_{u c}=P_{u c, \text { module }} / V_{T, u c} \\
V_{T, u c}=q_{u c} / C_{u c}-I_{u c} R_{u c}
\end{gathered}
$$

Substituting Equation (21) into Equation (22) and solving yields

$$
\begin{gathered}
V_{T, u c}^{2}=q_{u c} / C_{u c} \cdot V_{T, u c}-P_{u c, \text { module }} R_{u c} \\
V_{T, u c}=\frac{1}{2}\left(\frac{q_{u c}}{C_{u c}}+\sqrt{\frac{q_{u c}}{C_{u c}}-4 P_{u c, \text { module }} R_{u c}}\right)
\end{gathered}
$$

$V_{T, u c}$ can then be substituted back into Equation (21) to obtain the ultracapacitor current. Then, the state equation for the capacitor is

$$
\dot{q}_{u c}=I_{u c}-\frac{q_{u c}}{R_{u c} C_{u c}}
$$

Then, for the complete ultracapacitor pack,

$$
\begin{gathered}
I_{u c, p a c k}=I_{u c} \cdot N_{p c} \\
V_{T, u c, \text { pack }}=V_{T, u c} \cdot N_{s c} \\
R_{u c, p a c k}=R_{u c} \cdot \frac{N_{s c}}{N_{p c}}
\end{gathered}
$$

where $I_{u c, p a c k}$ is the total current going to or from the UC pack, $V_{T, u c}$ is the terminal voltage of the overall UC pack, and $R_{u c, p a c k}$ is the equivalent series resistance of the entire pack.

\subsection{Battery Aging Model}

This research uses the cycle-life aging model presented in Reference [34], and develops it here into an aging model that can be used in dynamic control of the energy storage systems. Reference [34] models the cycle life of a battery as a function of depth of discharge DoD, charging current $I_{\mathcal{c}}$, discharging current $I_{d}$, and temperature $T$.

$$
C L=g\left(D o D, I_{c}, I_{d}, T\right)
$$

This model starts as a simple curve fit of cycle life to depth-of-discharge at a reference point of $I_{C}=1 C, I_{d}=1 \mathrm{C}, T=25^{\circ} \mathrm{C}$. This baseline cycle life is denoted as $C L_{D o D}$. Then,

$$
C L_{D o D}=a_{1} e^{a_{2} \cdot D o D}+a_{3} e^{a_{4} \cdot D o D}
$$

where the $a_{i}$ terms are curve fit parameters. The cycle life is then obtained by modifying $C L_{D o D}$ based on the actual operating $I_{c}, I_{d}$, and $T$.

$$
C L=C L_{D o D} \cdot A_{I_{d}} \cdot A_{I_{c}} \cdot A_{T}
$$

where

$$
A_{I_{d}}=\frac{a_{5} e^{a_{6} \cdot I_{d}}+a_{7} e^{a_{8} \cdot I_{d}}}{a_{5} e^{a_{6}}+a_{7} e^{a_{8}}}
$$




$$
\begin{gathered}
A_{I_{c}}=\frac{a_{9} e^{a_{10} \cdot I_{c}}+a_{11} e^{a_{12} \cdot I_{c}}}{a_{9} e^{a_{10}}+a_{11} e^{a_{12}}} \\
A_{T}=\frac{a_{13} T^{3}+a_{14} T^{2}+a_{15} T+a_{16}}{25^{3} a_{13}+25^{2} a_{14}+25 a_{15}+a_{16}}
\end{gathered}
$$

where the $a_{i}$ terms are, again, curve fit parameters. The $a_{5}-a_{8}$ parameters are found from a curve fit of cycle life to varying $I_{d}$ for $I_{c}=1 C, T=25^{\circ}$, and $D o D=100 \%$. The $a_{9}-a_{12}$ parameters are found from a curve fit of cycle life to varying $I_{c}$ for $I_{d}=1 C, T=25^{\circ}$, and $D o D=100 \%$. The $a_{13}-a_{16}$ parameters are found from a curve fit of cycle life to varying $T$ for $I_{d}=1 C, I_{c}=1 C$, and $D o D=100 \%$.

The cycle life model in [34] assumes uniform charge and discharge cycles over the life of the battery. The Palmgren-Miner (PM) rule can be used, then, to handle the non-uniform cycles of vehicle operation. This method, originally developed for analyzing material fatigue life, has been shown to effectively approximate the battery health over non-uniform charge and discharge cycles [35-37]. Under the assumptions of this method, each charge and discharge cycle damages the battery an amount equal to the inverse of the cycle life at that cycle's operating conditions. In other words, if we assume a cycle $k$ with depth of discharge $D o D_{k}$, charge current magnitude $I_{c, k}$, discharge current magnitude $I_{d, k}$, and temperature $T_{k}$, then the cycle life for these operating conditions is $C L_{k}$. Under the PM rule, this cycle damages the battery an amount $D_{k}$ given by

$$
D_{k}=1 / C L_{k}
$$

Damage accumulates linearly for each charge and discharge cycle. Therefore, the damage from each individual cycle can be summed to find the total damage. The total damage $D_{\text {tot }}$ through the $k$-th cycle is therefore

$$
D_{\text {tot }}(k)=\sum_{i=1}^{k} D_{i}
$$

where each $D_{i}$ represents the damage from a single cycle with operating conditions $D o D_{i}$, $I_{c, i}, I_{d, i}$, and $T_{i}$. In this way, the damage of individual cycles with unique operating conditions is summed to obtain a total measure of battery health. Zero total damage indicates that the battery is at its beginning of life, while total damage of one indicates the battery's end of life. Battery end-of-life corresponds to a $20 \%$ capacity fade, therefore the capacity fade $C F$ can be put in terms of the damage as

$$
C F(k)=0.2 \cdot D_{\text {tot }}(k)
$$

The above method requires full knowledge of the charge and discharge time histories, which is not practical for use in energy management; the EMS must act at a much faster rate than the pace at which these cycles develop. It is possible, however, that the EMS could determine how a control decision might cause the damage from the current cycle to lessen or grow. For instance, imagine a battery operating at conditions of $D o D_{j}, I_{c, j}, I_{d, j}, T_{j}$. Then, let the energy management system make some decision that produces new operating conditions of $D o D_{k}, I_{c, k}, I_{d, k}, T_{k}$. Using Equations (29) and (35), the change in damage $\Delta D$ due to the EMS's decision can be computed as

$$
\Delta D=D_{k}-D_{j}=\frac{1}{g\left(D o D_{k}, I_{c, k}, I_{d, k}, T_{k}\right)}-\frac{1}{g\left(D o D_{j}, I_{c, j}, I_{d, j}, T_{j}\right)}
$$

Then, an energy management strategy could incorporate Equation (38) for a measure of potential battery damage. In this way, the strategy would try to minimize the damage from the control decision made at each time step. Note that, when controlling aging in this manner, the EMS can only be aware of the $D o D$ up until the current point in time and can only assess damage relative to the current $D o D$, while the "true" aging depends on the size 
of the completed cycle. Despite this discrepancy, this method still proves an effective way to control battery aging, as will be shown in later sections.

The resistance growth model in Reference [34] can be treated in an identical manner to Equations (29)-(38). The capacity fade and resistance growth models both use rainflow counting, as in [38], to determine the aging from the irregular cycling operations experienced while a vehicle is in operation. For simplicity, it is assumed that the battery operates at a constant internal temperature of $35^{\circ} \mathrm{C}$.

\subsection{Ultracapacitor Aging}

A novel aspect of this research is that ultracapacitor aging is considered in addition to battery aging. Reference [6] provides the following model for ultracapacitor aging. This model is based on Eyring's Law, a chemical rate equation which gives an ultracapacitor lifespan based on the operating voltage and internal temperature where aging increases exponentially as the voltage and temperature increase. Then, the aging rate at an instance in time is based on the inverse of the lifespan at the given operating conditions. In this model, $S o A$ is the state of aging that characterizes both capacitance fade and resistance growth, where a SoA of 0 indicates start-of-life and of 1 indicates end-of-life.

$$
\frac{d S o A}{d t}=\frac{1}{T_{\text {life }}^{r e f}} \cdot \exp \left(\ln (2) \frac{\theta_{c}-\theta_{c}^{r e f}}{\theta_{0}}\right) \cdot\left(\exp \left(\ln (2) \frac{V-V^{r e f}}{V_{0}}\right)+K\right)
$$

where $\theta_{c}$ and $V$ are the UC temperature and voltage, respectively, and the remaining variables $\left(T_{\text {life }}^{\text {ref }} \theta_{c}^{\text {ref }}, \theta_{0}, V^{r e f}, V_{0}\right.$, and $K$ ) are parameters fitted to experimental data. Then, from [6], the instantaneous capacitance $C_{u c}$ and internal resistance $R_{u c}$ are given by

$$
\begin{gathered}
C_{u c}=C_{u c, 0} \times(0.95-0.15 \cdot \text { So } A) \\
R_{u c}=R_{u c, 0} \times(1-0.3 \cdot \text { So } A)^{-1}
\end{gathered}
$$

where $C_{u c, 0}$ and $R_{u c, 0}$ are the initial values of $C_{u c}$ and $R_{u c}$.

This model can be used in control without modification. The standard end-of-life conditions for ultracapacitors are defined similarly to batteries: when the UC capacitance has faded by $20 \%$ [6]. It is assumed that the ultracapacitor operates at a constant internal temperature of $55{ }^{\circ} \mathrm{C}$, estimated from the operating conditions found in [39].

\subsection{Aging and Fuel Economy Trade-Off}

This paper analyzes the trade-off between battery aging and energy consumption in an electric vehicle with a HESS. This section briefly touches on why there must necessarily be a trade-off.

Consider the two paths in which power can flow through the HESS, shown in Figure 5. Consider the first case, where power flows primarily or entirely along the upper path, directly between the battery and the electric motor. In this case, the ultracapacitor is used marginally or not at all, meaning there is little to no change in either energy consumption or battery aging compared to a conventional EV that does not include an ultracapacitor. Next, consider a case where power flows primarily on the lower path, such that the ultracapacitor is heavily used and acts as a buffer between the battery and the electric motor. On one hand, the power flowing to or from the battery can be controlled to reduce aging factors such as large currents. On the other hand, the ultracapacitor introduces new resistances to the energy storage system as well as converter inefficiencies, resulting in increased losses. Therefore, any use of the ultracapacitor to reduce battery aging necessarily incurs new energy losses from the internal resistance of the ultracapacitor. In short, battery lifespan cannot be extended without an increase in energy consumption. 


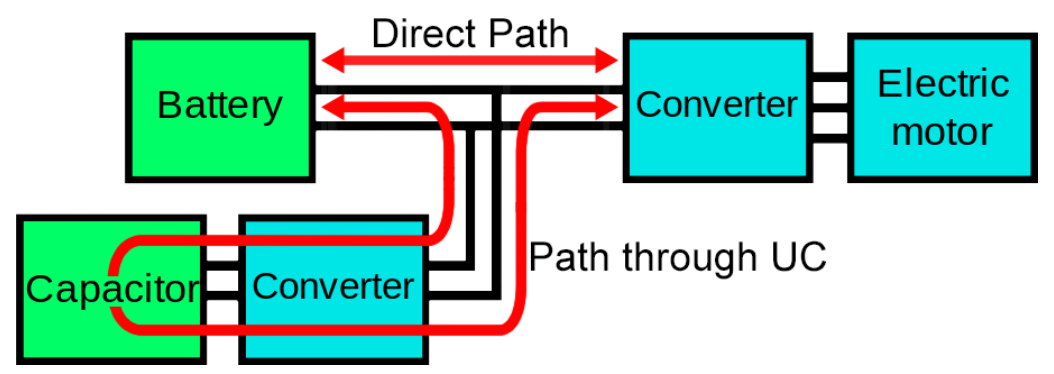

Figure 5. HESS power paths. Power on the direct path between battery and motor experiences minimal losses, while power on the path through the UC experience additional losses from the UC internal resistance.

\section{Control}

In order to fully investigate the benefits of aging-aware control, seven different types of energy management systems are considered:

1. DDP with Battery Aging Penalty, denoted DDP-B;

2. DDP with Energy Loss Penalty and Battery and Capacitor Aging Penalties, denoted DDP-EC;

3. DDP with Battery Power Penalty, denoted DDP-P;

4. SDP with Battery Aging Penalty, denoted SDP-B;

5. SDP with Energy Loss Penalty and Battery and Capacitor Aging Penalties, denoted SDP-EC;

6. SDP with Battery Power Penalty, denoted SDP-P;

7. Load Leveling, denoted LL.

\subsection{Dynamic Programming}

The first six strategies use DP to generate an optimal controller, with the first set of three using DDP and the second set of three using SDP. The development of DP for HEV energy management has been covered by a variety of literature, such as [40-43]. For both DDP and SDP, the optimization problem considers a discrete-time dynamic system

$$
x(k+1)=f(x(k), u(k), w(k))
$$

where $x(k)$ is the state vector at time $k, u(k)$ is the control vector, and $w(k)$ is a vector of any inputs or disturbances. $x, u$, and $w$ are assumed to exist in finite ranges $x \in X, u \in U$, and $w \in W$.

DDP uses exact knowledge of the driver behavior, including knowledge of future behavior, to minimize a given cost function over the complete driving trajectory.

$$
J=\sum_{k=0}^{N} L(x(k), u(k), w(k))
$$

where $L(x, u, w)$ is an instantaneous cost function, and $x, u$, and $w$ are the state variables, controlled variables, and system inputs, respectively. Equation (43) is minimized by solving a recursive cost-to-go function

$$
\begin{aligned}
V(x, N) & =\min _{u \in U}\{L(x, u, w(N))\} \\
V(x, k)= & \min _{u \in U}\{L(x, u, w(k))+V(f(x, u, w(k)), k+1)\} \\
& \text { for } k=N-1, \ldots, 0
\end{aligned}
$$

starting at $k=N$ and working backward through time to $k=0$. The key point of the DDP method is that, at each optimization step, the entire cost from the current time $k$ to the final time $N$ is minimized, not just the instantaneous cost. $V(x, k)$ is evaluated for each $x \in X$, so 
that $V(f(x, u, w(k)), k+1)$ can be interpolated from the prior update. The optimal control is found by a direct search of $u \in U$. Then, the optimal control $u^{*}$ is given by

$$
\begin{aligned}
u^{*}(x, k)=\arg \min _{u \in U}\{L(x, u, w(k))+ \\
V(f(x, u, w(k)), k+1)\}
\end{aligned}
$$

Meanwhile, SDP uses a stochastic model of driver behavior to anticipate the future driver power or torque requests and minimize the expected value of a given cost function

$$
J=\mathbf{E}\left[\sum_{k=0}^{N} \gamma^{k} L(x(k), u(k), w(k))\right]
$$

where the function $\mathbf{E}[\cdots]$ denotes an expected value, and $\gamma$ is a discount factor $0<\gamma<1$ that allows the cost function to converge as $k \rightarrow \infty$. Equation (47) is again minimized with a recursive cost-to-go function

$$
\begin{aligned}
V(x, w, N) & =\min _{u \in U}\{L(x, u, w)\} \\
V(x, w, k) & =\min _{u \in U}\{L(x, u, w)+\gamma \cdot \mathbf{E}[V(f(x, u, w), w, k+1)]\} \\
& \text { for } k=N-1, \ldots, 0
\end{aligned}
$$

where, this time, the expected future costs are considered, rather than the exact future costs.

The SDP problem can be treated as a finite horizon problem, where $N$ is a fixed number of updates. Alternatively, it can be treated as an infinite horizon problem, where $\mathrm{N}$ is arbitrarily large and the updates to the cost-to-go function are carried out until the control policy converges, in other words

$$
V(x, w, k)=V(x, w, k+1) \forall x \in X \text { and } u \in U .
$$

As noted earlier, a value of $0<\gamma<1$ ensures convergence of the number as $N \rightarrow \infty$ [44]. Then, the optimal control $u^{*}$ is given by

$$
u^{*}(x, w)=\arg \min _{u \in U}\{L(x, u, w)+\gamma \cdot \mathbf{E}[V(f(x, u, w), w, 1)]\} .
$$

That is, the control optimizes the final update of the cost-to-go function. Although the SDP problem is solved backwards in time like the DDP problem, the resulting control policy is both time-invariant and causal. This is because the SDP problem does not require future knowledge of $w$; instead, it relies on the time-invariant stochastic model.

For this research, the state variables are the ultracapacitor state of charge $S O C_{c}$ and the battery depth of discharge for the current cycle $D o D$. The controlled variable is the power allotted to ultracapacitor $P_{u c}$. The driver power request $P_{r e q}$ is an input to the controller. For DDP, it is a precisely known function of time, while, for SDP, the future power request is estimated from the current driver power request and the current vehicle wheel speed $\omega_{\text {wh }}$, based on a stochastic model as described in [40].

It should be noted that, in general, dynamic programming control strategies are considered too computationally expensive to run in real time on a vehicle [5]. Instead, the control policy must be computed off-line and be implemented on the vehicle using a lookup table. This approach requires quantizing the variables into discrete grids of points; linear interpolation can then be used to find the optimal control at any given operating point. The implementation of such lookups tables has been shown to operate well in real time [45].

The three strategies employed by DDP and SDP in this research have a component of their respective instantaneous cost functions $L(x, u, w)$ to penalize battery aging and a component to penalize deviation of the UC SOC from a target value $S O C_{c, t g t}=60 \%$. The 
SOC deviation penalty serves two purposes: first, it helps to maintain the UC's readiness to handle large currents. If the UC is near its maximum charge, it may be unable to accept a large charging power request, and if the UC is near its minimum, it will be unable to accept a large discharging power request, both of which can strain the battery. Keeping the charge near a central value combats this problem. Second, by varying the penalty on the deviation from the target value, the extent to which the ultracapacitor is used for aging control can be tuned, allowing for a better comparison of lifespan improvements between simulation cases. The manner in which the instantaneous cost functions penalize aging varies, as described below.

The first strategy, employed by DDP-B and SDP-B, directly penalizes battery aging according to

$$
L(x, u, w)=\left(S O C_{c}-S O C_{c, t g t}\right)^{2}+Q_{1, \Delta D} \cdot \Delta D
$$

where $\Delta D$ is the damage to the battery as a result of a given control decision, as given in Equation (38), and $Q_{1, \Delta D}$ is a tuned weighting parameter. This strategy is denoted as DP-B when referring to the DDP-B and SDP-B types together.

The second, used for DDP-EC and SDP-EC, penalizes a combination of battery aging, ultracapacitor aging rate, and electrical energy losses according to

$$
L(x, u, w)=Q_{2, S O C}\left(S O C_{c}-S O C_{c, t g t}\right)^{2}+Q_{2, \Delta D} \cdot \Delta D+Q_{2, S O A} \cdot \frac{d S o A}{d t}+Q_{2, l o s s} E_{l o s s}
$$

where $E_{\text {loss }}$ is the energy losses from the battery and ultracapacitor, obtained from

$$
E_{l o s s}=R_{e q} I_{b a t t}^{2}+R_{u c, p a c k} I_{u c, p a c k}^{2}
$$

where $R_{e q}$ is the battery pack series resistance, $I_{b a t t}$ is the current through the battery, $R_{u c, p a c k}$ is the ultracapacitor pack series resistance, and $I_{u c, p a c k}$ is the current through the ultracapacitor pack, per the models presented in Section 2.1. Returning to Equation (53), the $Q_{2, i}$ terms are weighting parameters for their respective elements in the cost function. The three weighting parameters $Q_{2, \Delta D}, Q_{2, S O A}$, and $Q_{2, \text { loss }}$ are set according to industrial average prices for lithium-ion batteries, ultracapacitors, and energy from the electrical grid [46,47], such that the battery aging, ultracapacitor aging, and energy loss terms are all equally weighted based on their real-world values. Then, the remaining term $Q_{2, S O C}$ is used to tune the strategy. This strategy is denoted as DP-EC when referring to the DDP-EC and SDP-EC types together.

The third and final strategy does not directly penalize aging but rather penalizes large power going to or from the battery

$$
L(x, u, w)=\left(S O C_{c}-S O C_{c, t g t}\right)^{2}+Q_{3, P} \cdot P_{\text {Batt }}^{2}
$$

where $Q_{3, P}$ is a tuned weighting parameter and $P_{\text {batt }}$ is the power going to or from the battery, per Equation (12). In this way, we limit battery damage using only simple knowledge of how the battery ages - that large currents to and from the battery degrade it. Thus, we can distinguish the benefits of direct aging control in the DDP,-B, SDP-B, DDP-EC, and SDP-EC strategies from the benefits of DP control generally. This strategy is denoted as DP-P when referring to the DDP-P and SDP-P types together.

In this research, DDP is used to obtain the global-optimal control strategy for a given cost function and represents the best-case scenario for a controller type. SDP, on the other hand, represents a causal, implementable controller and offers a more realistic understanding of the capabilities of a given cost function design. Because it is causal, it is also a better comparison to the Load Leveling controller. It should be noted that it is possible to adapt the results of DDP optimization into a causal rule base; however, this method is not used in this research. 


\subsection{Load-Leveling}

The final strategy considered is a simple method called "Load-Leveling." In this method, the battery is assigned a maximum allowable current for charging and discharging, $I_{b, \max }$, which corresponds to minimum and maximum battery powers $P_{b, \min }$ and $P_{b, \max }$. $P_{b, \min }$ provides the limit on power going into the battery while charging (negative values of $\left.P_{b a t t}\right)$ and $P_{b, \max }$ provide the limit on discharging. Any power request from the driver that exceeds the allowable amount is handled by the ultracapacitor.

$$
P_{u c}= \begin{cases}P_{\text {req }}-P_{b, \text { max }}, & P_{\text {req }}>P_{b, \text { max }} \\ P_{\text {req }}-P_{b, \text { min }}, & P_{\text {req }}<P_{b, \text { min }} \\ P_{\text {reset }}, & \text { otherwise }\end{cases}
$$

where $P_{\text {reset }}$ is a small amount of power from the battery used to return the ultracapacitor SOC to a target value of $S O C_{c, t g t}=60 \%$.

$$
P_{\text {reset }}= \begin{cases}13 \mathrm{~kW}, & S O C_{c}>S O C_{c, t g t} \\ -13 \mathrm{~kW}, & S_{\mathrm{C}} \mathrm{C}_{c}<S O C_{c, \text { tgt }} \\ 0 & \text { otherwise }\end{cases}
$$

The $13 \mathrm{~kW}$ value corresponds approximately to a $0.1 \mathrm{C}$ battery charge or discharge rate, considered sufficiently low to not majorly affect the battery aging. The particular value of $I_{b, \max }$ is varied to tune the response of the controller.

This controller serves as a lower bound for EMS performance, as it has neither an aging model nor any form of optimal control.

\section{Case Study}

The model and developed controllers are, in this section, used for a case-study analysis of aging-aware energy management: simulation is used to determine how the various strategies perform relative to each other.

Each strategy is simulated on the Manhattan Bus Cycle (MBC) drive cycle [48] for an array of different controller tunings.

1. DDP-B and SDP-B had the $Q_{1, \Delta D}$ parameter varied from $10^{4}$ to $10^{10}$;

2. DDP-EC and SDP-EC had the $Q_{2, S O C}$ parameter varied from $10^{-4}$ to $10^{2}$;

3. DDP-P and SDP-P had the $Q_{3, P}$ parameter varied from $10^{-14}$ to $10^{-11}$;

4. LL has the $I_{b, \max }$ parameter varied from $2 \mathrm{C}$ to $0.8 \mathrm{C}$.

The range of weights is determined by looking at orders of magnitude of the element of the cost functions. For instance, for Equation (55), the $\left(S O C_{c}-S O C_{c, t g t}\right)^{2}$ term has an order of magnitude of, at most, $10^{-2}$, while the $P_{b a t t}^{2}$ term can have an order of magnitude of up to $10^{10}$. Thus, tuning of $Q_{3, P}$ begins at $Q_{3, P}=10^{-12}$ and is varied from that point.

Additionally, a single baseline case that does not use the ultracapacitor is simulated. This corresponds to $Q_{1, \Delta D}=0, Q_{2, S O C} \rightarrow \infty, Q_{3, P}=0$, or $P_{\max } \rightarrow \infty$.

Simulations begin with both the battery and ultracapacitor at the beginning of their life. After each full discharge cycle, the aging of the battery and ultracapacitor are measured, and the capacity, capacitances, and resistances of the HESS are updated. For the purpose of measuring aging, the battery is assumed to recharge at a rate of $0.5 \mathrm{C}$. Simulations are then repeated until the battery reaches the end of its life, at which point the cycle life, ultracapacitor state-of-aging, and average energy consumption are measured and recorded.

The above is repeated for three HESS designs: a small ultracapacitor unit $N_{p c}=10$, a middle-sized ultracapacitor unit $N_{p c}=40$, and a large ultracapacitor unit $N_{p c}=100$. Both DDP and SDP simulations are performed for the $N_{p c}=100$ case, in order to establish that the SDP controllers will closely follow the DDP results. For the $N_{p c}=10$ and $N_{p c}=40$, only the causal controllers (SDP-B, SDP-EC, SDP-P, and LL) are simulated.

Energy consumption is measured in equivalent miles per gallon (MPGe), while battery aging is measured in capacity loss per mile. For ease of interpretation, the battery cycle life 
is converted to an approximate lifespan using an estimate of the average number of miles driven per year, $D_{\text {avg-year }}=34,000$ [49].

Finally, the cost-benefit of the HESS is determined. First, the value of the HESS is determined based on the industrial average price per $\mathrm{kWh}$ of $\$ 300 / \mathrm{kWH}$ for lithium ion batteries and $\$ 15,000 / \mathrm{kWh}$ ultracapacitors from [46] and on the battery and ultracapacitor size given in Section 2.1. This gives a battery value of $V_{\text {batt }}=\$ 38,760$ and an ultracapacitor value of $V_{u c}=\$ 13,021$. Additionally, an average electrical energy price of $V_{\text {nrg }}=\$ 0.1065 / \mathrm{kWh}$ for the U.S. is obtained from [47]. Costs and benefits are normalized by mile driven for a fair comparison between configurations. Then, the battery cost per mile $(B C P M)$ is determined from the miles driven over the life of the battery, denoted as "battery lifetime miles driven" (BLMD).

$$
B C P M=\frac{V_{\text {batt }}}{B L M D}
$$

The ultracapacitor cost per mile (UCCPM) is similarly determined, this time including a term for the ultracapacitor state of aging at the battery end-of-life (BEOL), So $A_{B E O L}$.

$$
U C C P M=S o A_{B E O L} \times \frac{V_{u c}}{B L M D}
$$

Finally, the energy costs per mile $(E C P M)$ are given as

$$
E C P M=\frac{V_{n r g} \times G G E}{M P G e}
$$

where GGE is the gasoline gallon equivalent to convert from gallons of gasoline to $\mathrm{kWh}$, $G G E=33.41 \mathrm{kWh} /$ gal. gasoline.

Then, the cost or benefit of the HESS can be determined by comparing the result to the nominal case where no UC is present. Letting the subscript nom denote the nominal case and $(k)$ denote any particular simulation, the benefit per mile $(B P M)$ is given by

$$
B P M(k)=\left(B C P M_{\text {nom }}-B C P M(k)\right)-U C C P M(k)+\left(E C P M_{\text {nom }}-E C P M(k)\right)
$$

where a positive benefit per mile indicates that value is being added to the system, while a negative value indicates that the cost of the UC outweighs the benefit it adds.

Finally, the payback time $T_{\text {payback }}$ (in years) for the HESS can be estimated from the UC value, average miles driven per year, and the benefit per mile.

$$
T_{\text {payback }}=V_{u c} \times \frac{1}{B P M(k)} \times \frac{1}{D_{\text {avg-year }}}
$$

Payback time assumes a positive benefit per mile. If the BPM is zero or negative, then a payback time does not exist.

\section{Results}

The simulation results are analyzed as follows: first, it is verified that the SDP controllers closely follow the DDP controllers. Next, the impact of aging-aware control on the causal controllers is assessed. Then, the effect of overuse of the ultracapacitor is discussed. Finally, the cost-benefit of the HESS is analyzed and discussed.

\subsection{Verification of DP Controllers}

First, the DDP and SDP methods are compared for the $N_{p c}=100$ case for each of the three DP cost functions, as given in Equations (52)-(55). These simulation results are shown in Figure 6. In the case of the DP methods with an incorporated aging model, the SDP controller closely tracks the global optimal DDP controller. For the cases that use a battery aging model, the lifespan of the SDP-controlled battery is typically within $1 \%$ of 
the DDP result for a given MPGe, while the difference is greater for the controller that only limits battery power, especially near the peak. These results demonstrate that the causal SDP controllers are able to closely match the DDP global optima and indicate that the SDP controllers behave as intended.

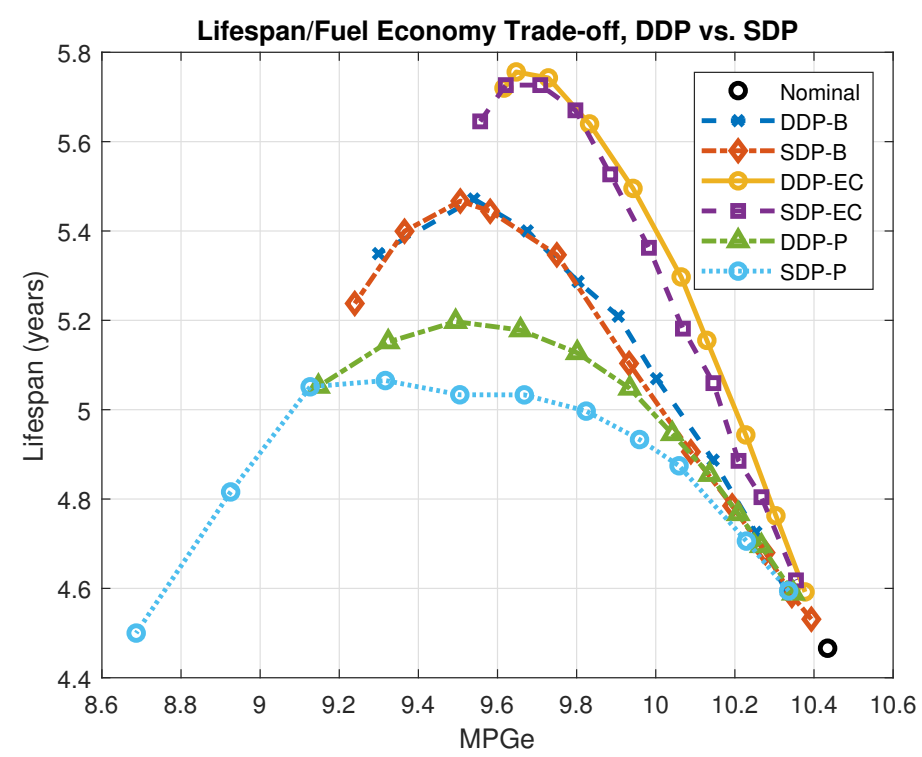

Figure 6. Energy consumption and battery aging for the DP-based methods for $N_{p c}=100$.

The DP results are summarized in Table 4. Note that the value for "Mean Life Difference" is the average difference in lifespan of an SDP controller compared to a DDP controller at any given operating MPGe value between the nominal point and the DDP peak. Again, the key result of these data is that the SDP controllers follow the DDP controllers within $1.7 \%$, and within $1.0 \%$ for the aging-aware control specifically. Comparisons of the different cost functions are discussed next.

Table 4. Comparison of DP Controllers for $N_{p c}=100$.

\begin{tabular}{cccccc}
\hline Type & $\begin{array}{c}\text { DDP Max } \\
\text { Lifespan } \\
\text { (Years) }\end{array}$ & $\begin{array}{c}\text { MPGe at } \\
\text { DDP Peak } \\
\text { (MPGe) }\end{array}$ & $\begin{array}{c}\text { SDP Lifespan } \\
\text { at DDP Peak } \\
\text { (Years) }\end{array}$ & $\begin{array}{c}\text { Difference } \\
\text { at Peak } \\
\mathbf{( \% )}\end{array}$ & $\begin{array}{c}\text { Mean Life } \\
\text { Difference } \\
\mathbf{( \% )}\end{array}$ \\
\hline DP-B & 5.47 & 9.54 & 5.46 & -0.27 & -0.45 \\
DP-EC & 5.76 & 9.65 & 5.73 & -0.51 & -0.95 \\
DP-P & 5.20 & 9.49 & 5.04 & -3.11 & -1.67 \\
\hline
\end{tabular}

\subsection{Effect of Aging-Aware Control}

Next, all four causal strategies (SDP-B, SDP-EC, SDP-P, and Load Leveling) are compared. The $N_{p c}=10$ case is shown in Figure 7, the $N_{p c}=40$ case is shown in Figure 8, and the $N_{p c}=100$ case is shown in Figure 9.

First, it can be seen that a larger HESS allows for greater improvements to battery lifespan. This is expected-the $N_{p c}=10 \mathrm{UC}$ can only reduce current to or from the battery by approximately $0.5 \mathrm{C}$, while the largest power request from the driver corresponds to $2.5 \mathrm{C}$. On the other hand, the $N_{p c}=100$ case can handle much larger power requests and can do much more to limit large battery current. However, these additional improvements come with a monetary cost, which is discussed more at the end of this section.

It is found across all three HESS sizing cases that the SDP-EC does the most to improve battery lifespan, offering a peak lifespan of 4.69 years at $10.15 \mathrm{MPGe}$, 5.16 years at $9.81 \mathrm{MPGe}$, and 5.72 years at $9.72 \mathrm{MPGe}$ for the $N_{p c}=10, N_{p c}=40$, and $N_{p c}=100$ cases, respectively. 


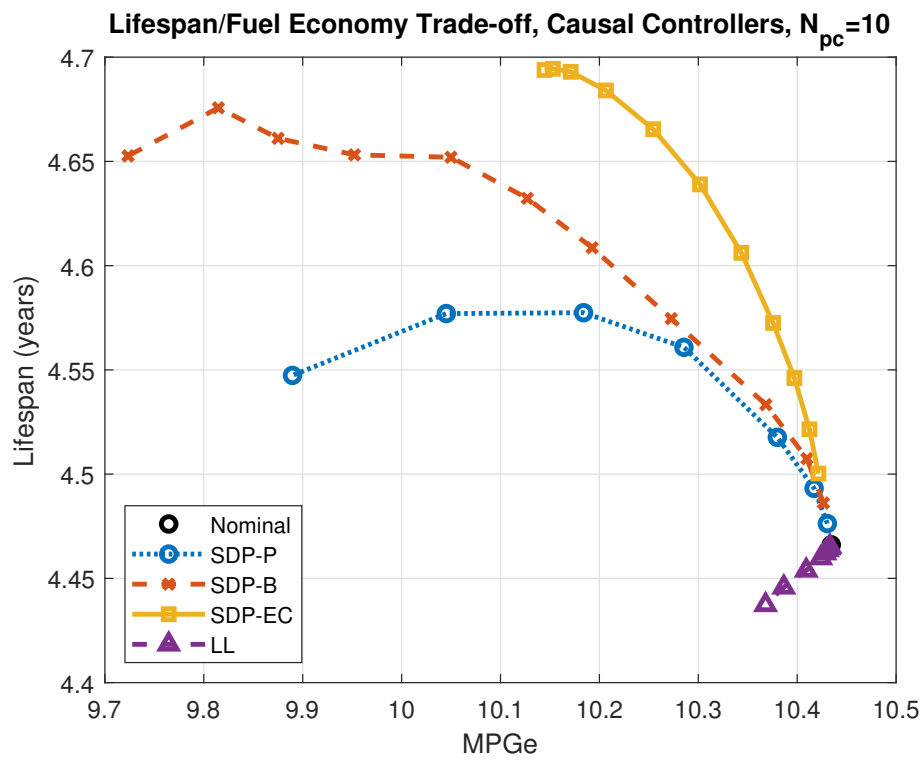

Figure 7. Comparison of energy consumption and battery aging for the four causal control methods, $N_{p c}=10$.

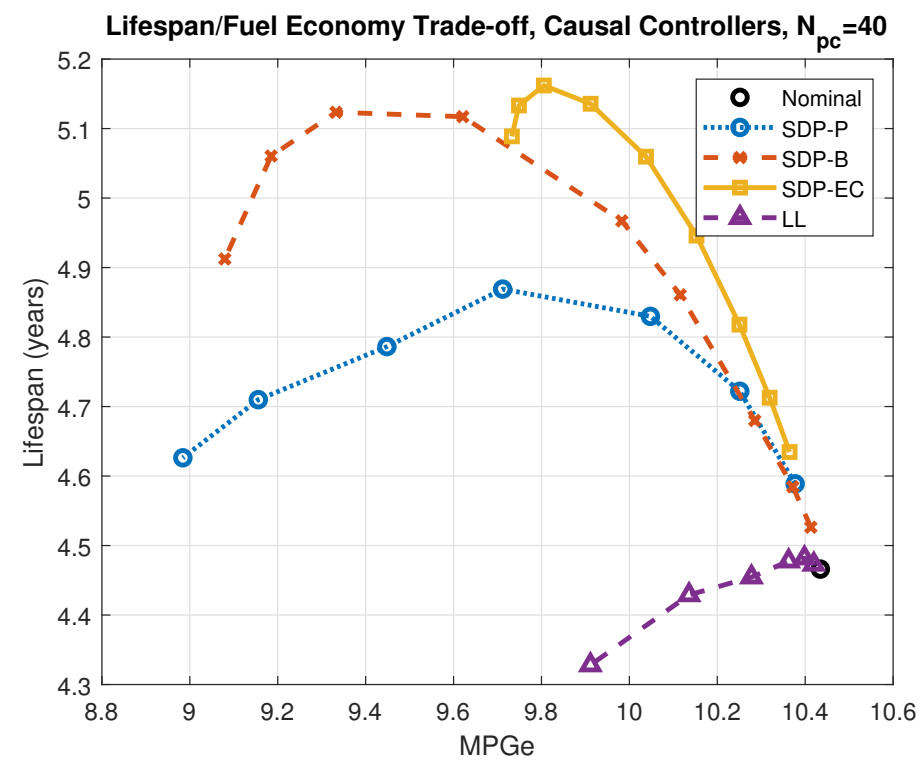

Figure 8. Comparison of energy consumption and battery aging for the four causal control methods, $N_{p c}=40$.

The SDP-B offers substantial lifespan improvements as well, however, not to the degree of SDP-EC. SDP-B exceeds the performance of the the two non-SDP strategies but does not improve lifespan as well as the SDP strategies that include direct aging control. Although SDP-P does substantially increase battery lifespan, it does not "understand" the aging mechanics—such as the different effect of charging and discharging currents, or how damage from large currents is multiplied at high DoD-resulting in smaller lifespan increases than the strategies that control aging directly. The performances of SDP-EC and SDP-B relative to SDP-P clearly indicate the power of aging-aware energy management.

Not only does SDP-EC offer the best increase in battery lifespan, it offers the best improvements to the overall energy consumption/battery aging trade-off. That is, for all three HESS sizes and for any given rate of energy consumption, the SDP-EC strategy offers the largest improvements to battery lifespan; further increases to lifespan incur the smallest increases to energy consumption. Not only is the peak lifespan improvements for 
the SDP-EC method higher than SDP-B and SDP-P, it reaches that peak at a lower MPGe than the peaks of the SDP-B and SDP-P curves. The performance of SDP-EC compared to SDP-B indicates the value of controlling ultracapacitor aging and energy losses in addition to battery aging.

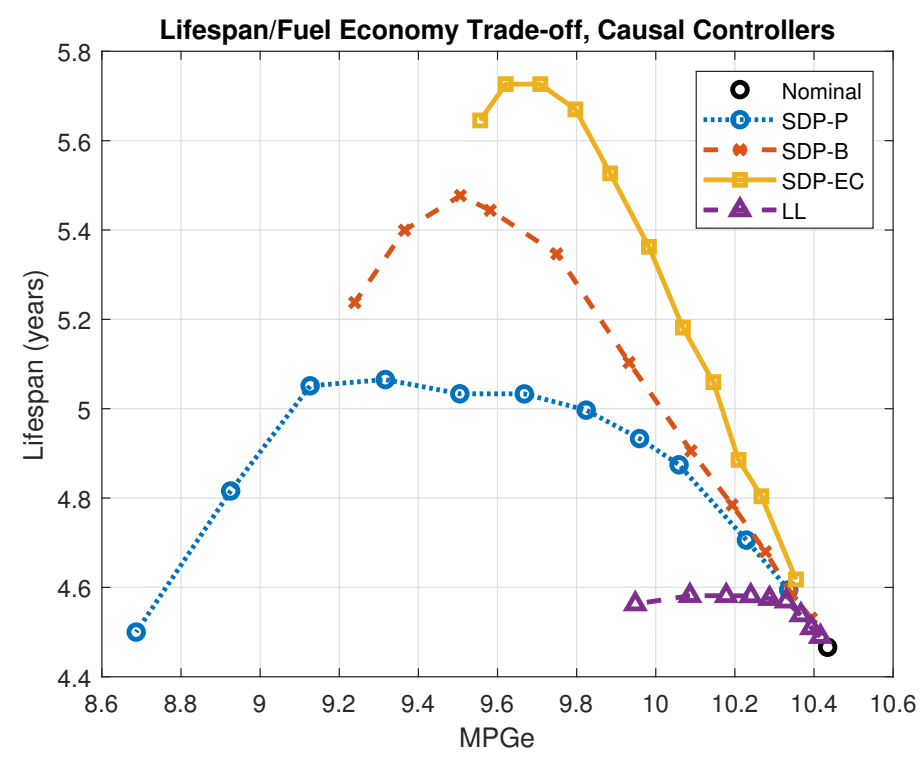

Figure 9. Comparison of energy consumption and battery aging for the four causal control methods, $N_{p c}=100$.

The baseline case, Load Leveling, does not perform well: in the $N_{p c}=10$ and $N_{p c}=40$ cases, it offers virtually no lifespan improvement at all. With the large HESS, although it is able to match the SDP performance at low levels of UC usage, it quickly reaches its peak before dropping off. In this case, Load Leveling offers a peak lifespan of only 4.58 years.

The average change in ultracapacitor state of aging, measured at the end of battery life, is plotted in Figure 10 for $N_{p c}=40$ as a representative case. Nominal aging-the aging of an ultracapacitor that is stored at the target $\mathrm{SOC}$ and at the temperature given in Section 2.3, and is otherwise unused-is found to be $\Delta S o A$ per year $=4.064 \%$. At low degrees of UC usage, all three SDP methods are shown to have UC aging near the nominal. However, as UC usage increases, the SDP-B and SDP-P methods are seen to have the UC aging rate grow-SDP-B, in fact, reaches a peak UC aging rate of $4.415 \%$ at $9.19 \mathrm{MPGe}$. On the other hand, SDP-EC is shown to have measurably less UC aging at high levels of UC usage. This is expected, as SDP-EC seeks to limit UC aging while SDP-B does not.

The $N_{p c}=10$ and $N_{p c}=100$ cases are not presented here; however, similar trends in UC aging per controller type are observed.

Taken together, these results indicate a clear benefit to using strategies with predictive power, and that predictive power combined with energy storage aging models incorporated into the control strategy offers the best way to increase battery lifespan. The results of the four causal strategies are summarized in Table 5 for the $N_{p c}=10$ case, Table 6 for the $N_{p c}=40$ case, and Table 7 for the $N_{p c}=100$ case. 


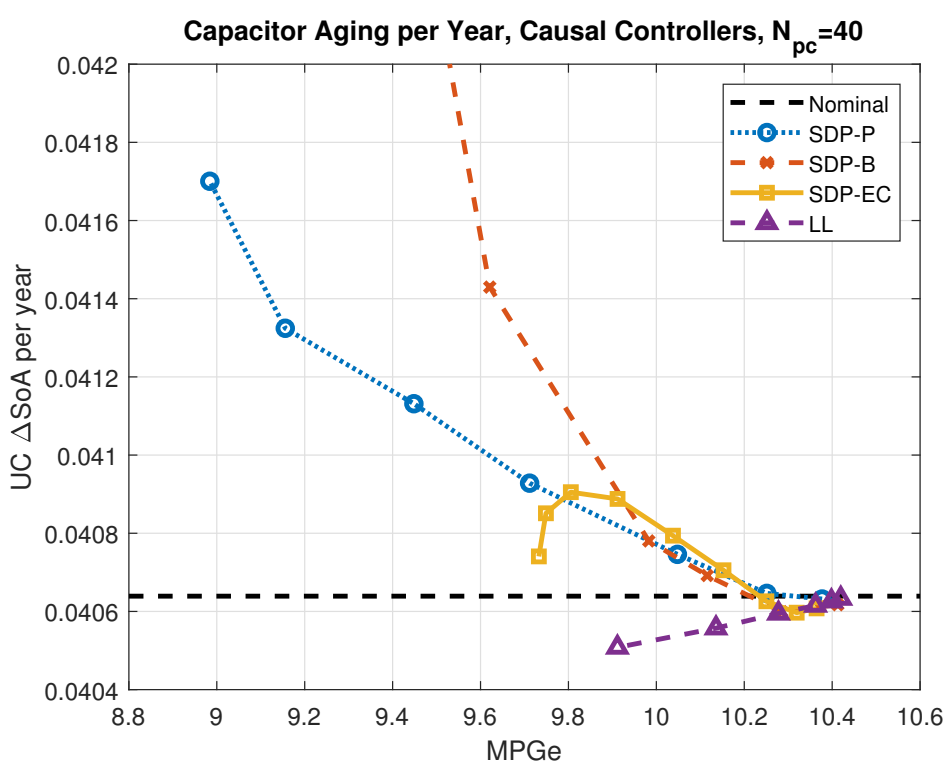

Figure 10. Comparison of energy consumption and UC aging for the four causal control methods, $N_{p c}=40$.

Table 5. Comparison of Causal Controllers, small HESS $\left(N_{p c}=10\right)$.

\begin{tabular}{cccccc}
\hline Type & $\begin{array}{c}\text { Peak } \\
\text { Lifespan } \\
\text { (Years) }\end{array}$ & $\begin{array}{c}\text { MPGe } \\
\text { at Peak } \\
\text { (MPGe) }\end{array}$ & $\begin{array}{c}\text { Lifespan } \\
\text { vs. Nominal } \\
(\%)\end{array}$ & $\begin{array}{c}\text { MPGe vs. } \\
\text { Nominal } \\
(\%)\end{array}$ & $\begin{array}{c}\text { UC } \Delta \text { SoA } \\
\text { Per Year } \\
\text { at Peak }\end{array}$ \\
\hline Nominal & 4.47 & 10.43 & - & - & 4.064 \\
SDP-B & 4.68 & 9.81 & 4.7 & -5.9 & 6.633 \\
SDP-EC & 4.69 & 10.14 & 5.1 & -2.8 & 4.587 \\
SDP-P & 4.58 & 10.18 & 2.5 & -2.4 & 4.105 \\
LL & 4.47 & 10.43 & - & - & 4.064 \\
\hline
\end{tabular}

Table 6. Comparison of Causal Controllers, mid-sized HESS $\left(N_{p c}=40\right)$.

\begin{tabular}{cccccc}
\hline Type & $\begin{array}{c}\text { Peak } \\
\text { Lifespan } \\
\text { (Years) }\end{array}$ & $\begin{array}{c}\text { MPGe } \\
\text { at Peak } \\
\text { (MPGe) }\end{array}$ & $\begin{array}{c}\text { Lifespan } \\
\text { vs. Nominal } \\
\text { (\%) }\end{array}$ & $\begin{array}{c}\text { MPGe vs. } \\
\text { Nominal } \\
\text { (\%) }\end{array}$ & $\begin{array}{c}\text { UC } \Delta \text { SoA } \\
\text { Per Year } \\
\text { at Peak }\end{array}$ \\
\hline Nominal & 4.47 & 10.43 & - & - & 4.064 \\
SDP-B & 5.12 & 9.62 & 14.7 & -7.8 & 4.138 \\
SDP-EC & 5.16 & 9.81 & 15.6 & -6.0 & 4.091 \\
SDP-P & 4.87 & 9.71 & 9.0 & -6.9 & 4.093 \\
LL & 4.48 & 10.40 & 0.4 & -0.3 & 4.063 \\
\hline
\end{tabular}

Table 7. Comparison of Causal Controllers, large HESS $\left(N_{p c}=100\right)$.

\begin{tabular}{cccccc}
\hline Type & $\begin{array}{c}\text { Peak } \\
\text { Lifespan } \\
\text { (Years) }\end{array}$ & $\begin{array}{c}\text { MPGe } \\
\text { at Peak } \\
\text { (MPGe) }\end{array}$ & $\begin{array}{c}\text { Lifespan } \\
\text { vs. Nominal } \\
\mathbf{( \% )}\end{array}$ & $\begin{array}{c}\text { MPGe vs. } \\
\text { Nominal } \\
\text { (\%) }\end{array}$ & $\begin{array}{c}\text { UC } \Delta \text { SoA } \\
\text { Per Year } \\
\text { at Peak }\end{array}$ \\
\hline Nominal & 4.47 & 10.43 & - & - & 4.064 \\
SDP-B & 5.48 & 9.51 & 22.6 & -8.9 & 4.100 \\
SDP-EC & 5.73 & 9.71 & 28.2 & -7.0 & 4.060 \\
SDP-P & 5.07 & 9.32 & 13.4 & -10.7 & 4.057 \\
LL & 4.58 & 10.09 & 2.6 & -3.3 & 4.046 \\
\hline
\end{tabular}




\subsection{Ultracapacitor Overuse}

In Section 2.4, it was established that there is necessarily a trade-off between battery aging and energy consumption when using a HESS to limit battery aging. A consequence of this is seen in every simulated controller, shown in Figures 6-9, at the tail end of each curve: as the ultracapacitor is used more and more extensively, energy consumption increases as more energy is lost from the ultracapacitor internal resistance. These losses must be made up for by discharging the battery more deeply - depth of discharge being a key aging factor, per the model presented in Section 2.2. At some point, increases to the $D o D$ aging factor outweigh the impact of decreases in the other aging factors, and battery lifespan eventually begins to decrease rather than increase. Thus, in cases where the ultracapacitor is used very heavily, attempts to control battery aging can have the opposite of the intended effect.

The $N_{p c}=100$ SDP-P results for energy losses are shown in Figure 11 as a representative example. Energy losses increase with increasing ultracapacitor usage, eventually leading to a decreased lifespan. This behavior emphasized the importance of tuning the energy management strategy properly. With poor tuning, it is possible for the HESS to do more harm than good. Similar trends are seen with the other control methods and other HESS sizes, but are not shown here.

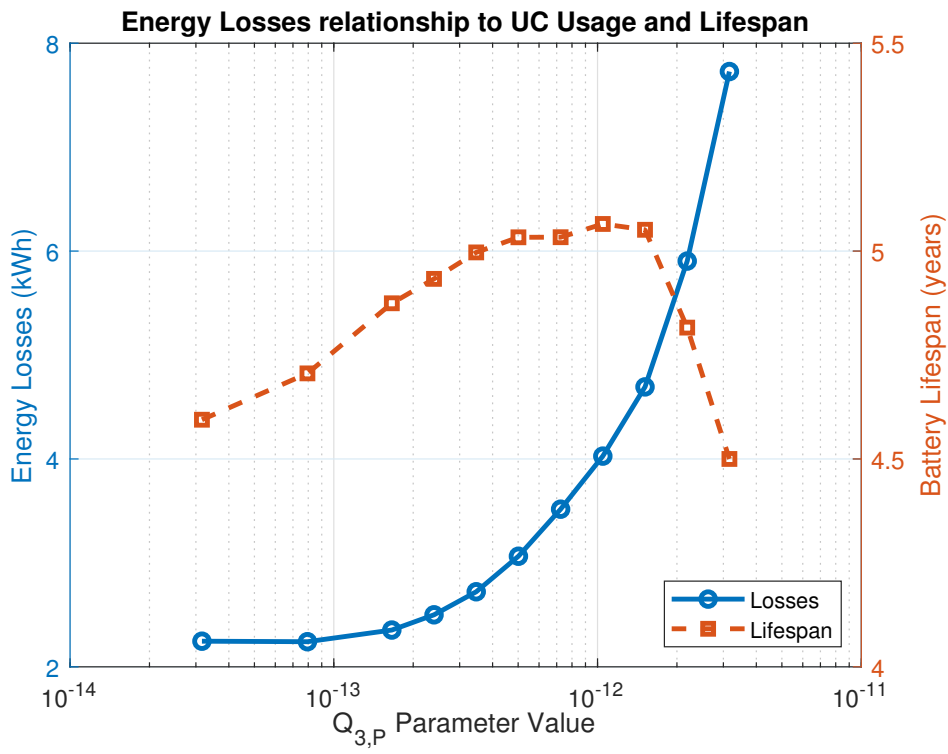

Figure 11. Comparison of energy losses (left axis) to battery lifespan (right axis) versus the $Q_{3, P}$ weighting parameter, where increasing $Q_{3, P}$ increases ultracapacitor usage.

\subsection{Cost-Benefit Analysis}

The cost-benefit of each simulated point is computed per Equations (58)-(61) and plotted versus MPGe in Figure 12 for the $N_{p c}=10$ case, in Figure 13 for the $N_{p c}=40$ case, and in Figure 14 for the $N_{p c}=100$ case. Positive values indicate that value is added to the system, while negative values indicate a cost.

In general, it is observed that the SDP-EC method offers clear value over the other methods: for any HESS sizing and for any given MPGe, the SDP-EC method offers the highest benefit per mile. In the $N_{p c}=10$ case, it was shown to be the only method that offered a positive return on investment. In the $N_{p c}=40$ case, the SDP-P and SDP-B methods did offer a positive return: the SDP-EC's maximum benefit per mile was over $50 \%$ greater than SDP-B and over $120 \%$ greater than SDP-P. The $N_{p c}=100$ case is similar to the $N_{p c}=10$ case in terms of relative performance: only the SDP-EC offers notable benefit. Although the SDP-B does offer a small positive return for some tunings, the maximum benefit of the SDP-B method is less than a quarter of the maximum benefit of the SDP-EC method. 


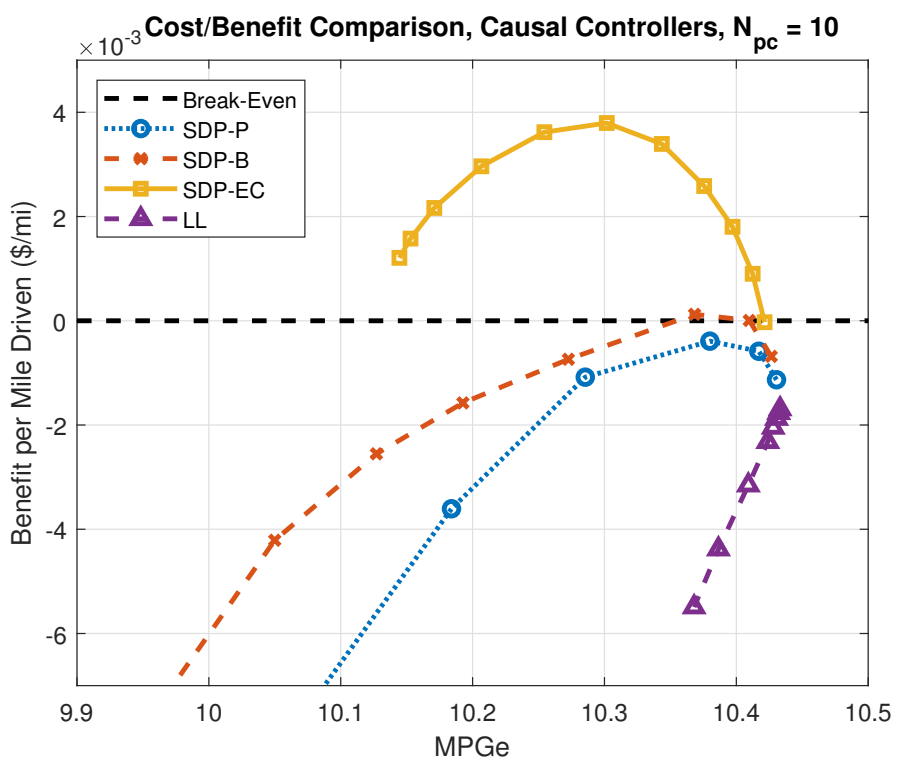

Figure 12. Cost-benefit analysis for the four causal control methods, $N_{p c}=10$.

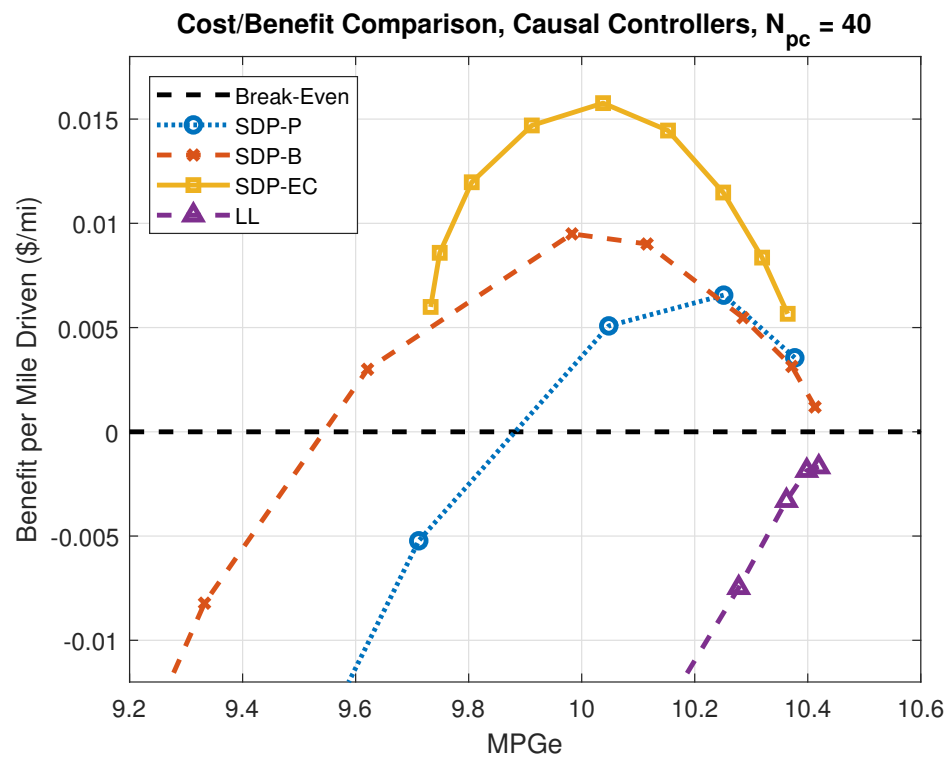

Figure 13. Cost-benefit analysis for the four causal control methods, $N_{p c}=40$.

Another takeaway from Figure 12 is that the peak economic benefit occurs at a higher MPGe (lower ultracapacitor utilization) than the peak lifespan increase. This makes intuitive sense: lifespan improvements level off near the peak while energy consumption continues to grow. Therefore, near the lifespan peak, the marginal improvement batterycost-per-mile is less than the marginal decrease in fuel economy. For the $N_{p c}=100$ SDP-EC method, there is not much difference between the peak lifespan increase (occurring at 9.71 MPGe) and the peak benefit (occurring at 9.80 MPGe); however, for a smaller HESS or for weaker strategies, the difference can be substantial: in the $N_{p c}=100$ case, the SDP-B peak lifespan increase is at $9.51 \mathrm{MPGe}$, which is effectively break-even in terms of value, while the peak benefit occurs at 9.75 MPGe. SDP-P has its peak benefit at 10.06 MPGe and peak lifespan at $9.32 \mathrm{MPGe}$; looking at the the SDP-EC method in the $N_{p c}=10$ case, the benefit at the peak lifespan increase is approximately half of the maximum possible benefit. Clearly, the economic factors should be considered when deciding on the controller tuning. 


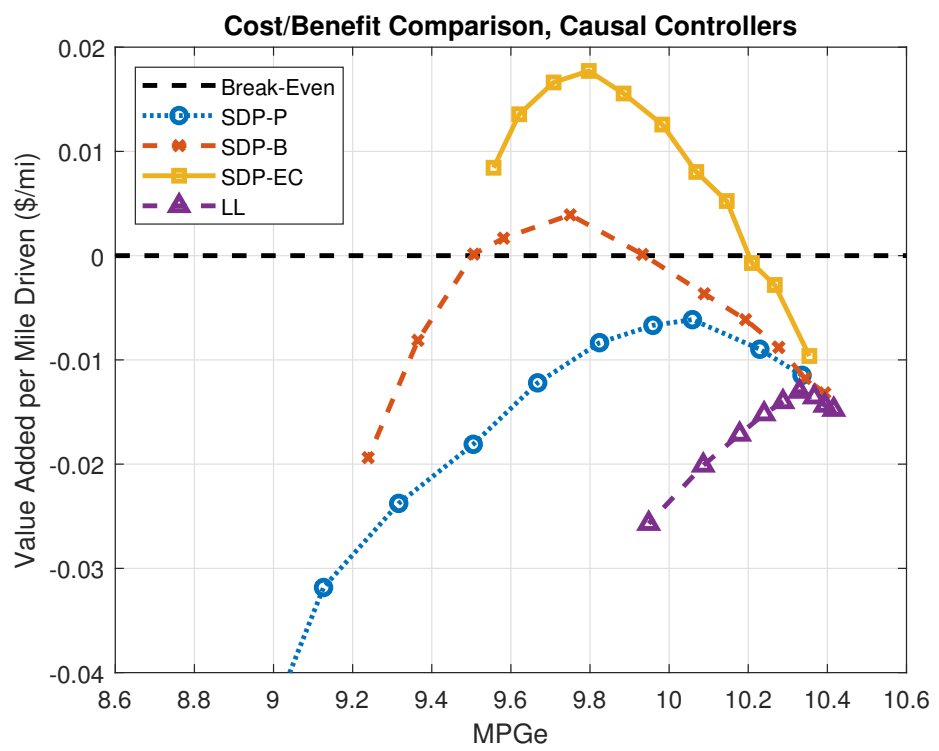

Figure 14. Cost-benefit analysis for the four causal control methods, $N_{p c}=100$.

Finally, the estimated payback time is computed for the maximum benefit of the SDP-EC method for all three cases using Equation (62). It is found that, for the given UC, battery, and energy costs, the small HESS $\left(N_{p c}=10\right)$ has a payback time of 11.3 years, the mid-sized HESS $\left(N_{p c}=10\right)$ has a payback time of 15.6 years, and the large HESS $\left(N_{p c}=100\right)$ has a payback time of 21.6 years.

In order to observe the full trend of the payback period for different ultracapacitor sizes, additional simulations are run for $N_{p c}$ equal to 2,5, and all increments of 10 between 10 and 100. The optimal EMS and optimal $Q_{2, S O C}$ are recomputed and the vehicle is simulated again for the new EMS and new UC size. The payback time and battery lifespan at the most cost-effective tuning for each $N_{p c}$ are then plotted in Figure 15. This shows that, although increasing the HESS does does improve the battery lifespan, the cost of the extra UCs exceeds the savings of that extra lifespan.

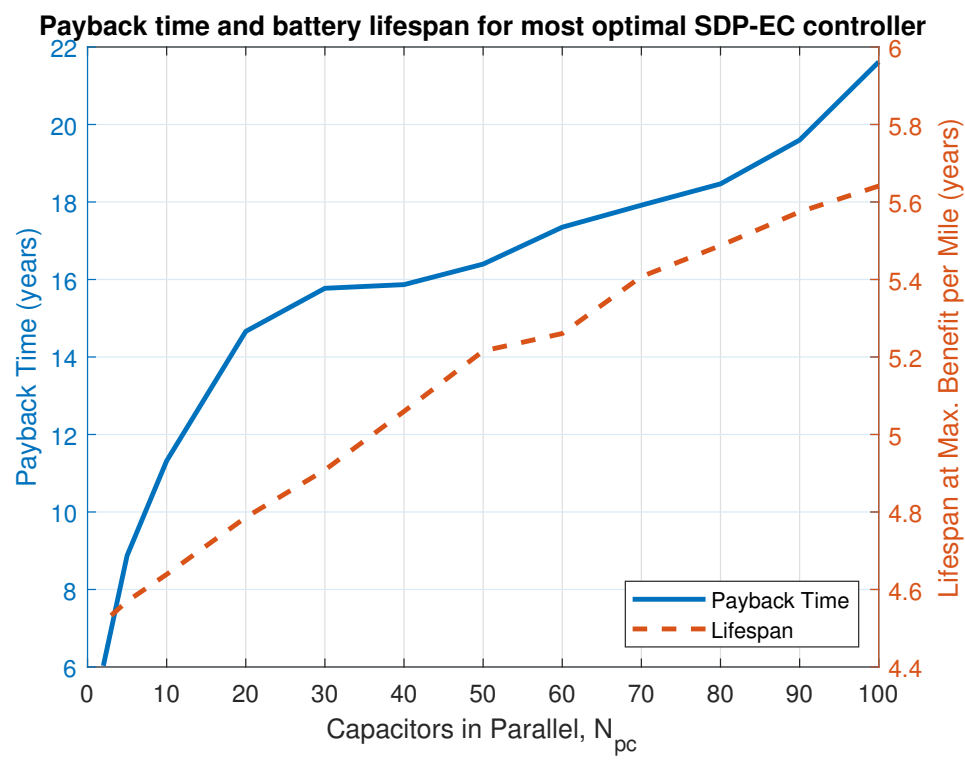

Figure 15. Estimated payback time for optimal SDP-EC controller with varying HESS size.

Finally, the authors note the sensitivity of the benefit per mile and the payback time period to assumptions about component pricing, energy pricing, and aging mechanisms. 
For instance: this research assumes that energy is priced at the US average across all sectors, $V_{n r g}=\$ 0.1067 / \mathrm{kWh}$ [47]. If, instead, energy was priced at the transportation sector average for the state of Illinois (such as for a Chicago Transit Authority bus), the energy price of $V_{n r g}=\$ 0.0632 / \mathrm{kWh}$, also from [47], would reduce the payback time by approximately $30 \%$. On the other hand, the California price $V_{n r g}=\$ 0.1280 / \mathrm{kWh}$ would increase the payback time by $30 \%$.

Alternatively, we can consider that battery and UC components use the pricing of reference [50] rather than [46] while maintaining $V_{n r g}=\$ 0.1067 / \mathrm{kWh}$; the increased battery and ultracapacitor prices from [50] result in a payback time of 6.9 years for the $N_{p c}=10 \mathrm{UC}$ and 13.7 years for the $N_{p c}=100 \mathrm{UC}$. On the other hand, the component prices of [51] would indicate that the HESS is not beneficial under any circumstance.

A different battery aging model in the literature [52], used in an array of battery and HESS control literature such as $[12,15,19,23,53,54]$, models lithium ion phosphate batteries as aging at up to $3 \times$ the rate of the model used in this research. If the battery ages even $1.5 \times$ the modeled rate, then we would see a payback period of 4.8 and 8.8 years for $N_{p c}=10$ and $N_{p c}=100$, respectively.

Finally, although battery end-of-life can be considered a hard limit for battery use based on range constraints, the ultracapacitor, on the other hand, can continue to be used beyond $80 \%$ capacitance fade. This would not be unreasonable, considering how Figure 15 shows that the effectiveness of the proposed control method is maintained as the number of cells (and over UC pack capacitance) is decreased. Therefore, if, for instance, the UCs were used until 70\% capacitance fade, then we would see a payback period of 7 and 12 years for $N_{p c}=10$ and $N_{p c}=100$, respectively. One could, alternatively, assume that the UC does not need to be replaced at all (setting UCCPM to 0), as UC life exceeds the 12 year lifespan of an individual transit bus [55]. However, there is still value to considering these replacement costs from the perspective of an entire vehicle fleet.

All this is to say: an engineer must take caution that a HESS is economically appropriate for a given application; there may be circumstances where a HESS is highly beneficial, and others where it may be impractical. With that said, this research has demonstrated that, for any HESS sizing and for any given MPGe, the SDP-EC method offers a larger increase to battery lifespan and a higher benefit per mile than the other considered methods. The important takeaway of this analysis is how proper control of the HESS is critical for maximizing both battery lifespan and HESS value, and that joint control of battery aging, UC aging, and energy losses is the most effective method to manage the HESS.

\section{Conclusions}

This paper develops controllable battery and ultracapacitor aging models for a HESS. Various energy management strategies are developed for the purpose of minimizing battery aging. As a case study, these models and control strategies are applied to a simulated electric bus to determine the battery lifespan and energy consumption of each strategy. An array of different HESS sizes and controller tunings are simulated in order to determine the trade-off between battery aging and energy consumption for each strategy. Additionally, the cost-benefit of the HESS is analyzed to determine the relative economic benefit of the proposed control strategies.

Simulation results showed that the SDP-EC method, which controls a weighted combination of battery aging, ultracapacitor aging, and energy losses, offers the biggest improvement to the aging-energy consumption trade-off across all considered HESS sizes. At its peak, this strategy offered a $28.2 \%$ increase in battery lifespan and required only a 7.0\% decrease in MPGe. The SDP-B method, which controls battery aging but neither ultracapacitor aging nor energy losses, was the next most effective controller, indicating the importance of including an aging model directly in the control.

Simulation results also demonstrated that excessive use of the ultracapacitor can, in fact, be detrimental to the lifespan of the battery. Ultracapacitor use incurs additional energy losses and, if the ultracapacitor is heavily used, then these losses can result in 
additional battery aging. Furthermore, the cost-benefit analysis showed that only the strategies that included direct aging control would reliably add value to the system; the SDP-EC method was the most proven manner of adding economic value to the HESS. These points, taken together, indicate the importance of control strategy selection and design.

Future work for this research includes the optimization of component sizing, given the proposed new methods of energy management. Additionally, work is ongoing to investigate the robustness of the control strategies for uncertainty in the battery and ultracapacitor models. Finally, other energy management strategies should be considered and compared to the methods here, such as DDP formed into a rule base or the Equivalent Consumption Minimization Strategy applied to aging control.

Author Contributions: K.M. and F.A. conceived and designed the experiments; K.M. developed the bus model performed the numerical experiments; K.M. and F.A. analyzed the data; K.M. wrote the paper. All authors have read and agreed to the published version of the manuscript.

Funding: This research received no external funding.

Institutional Review Board Statement: Not applicable.

Informed Consent Statement: Not applicable.

Acknowledgments: This work was supported by the University of California, Davis, Department of Mechanical and Aerospace Engineering.

Conflicts of Interest: The authors declare no conflict of interest.

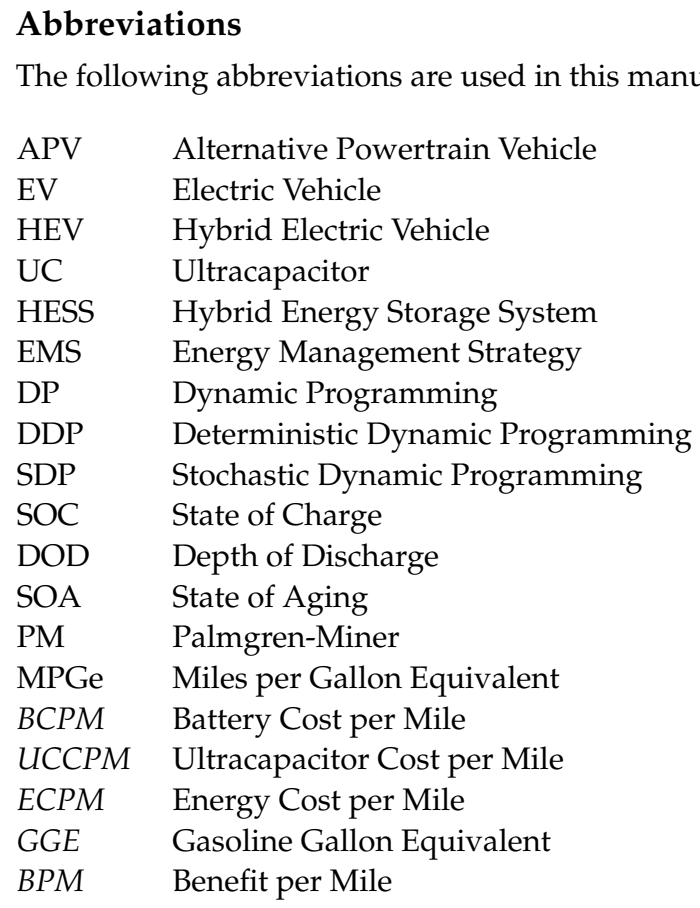

\section{References}

1. Lee, T.K.; Filipi, Z. Impact of Model-Based Lithium-Ion Battery Control Strategy on Battery Sizing and Fuel Economy in Heavy-Duty HEVs. SAE Int. J. Commer. Veh. 2011, 4, 198-209. [CrossRef]

2. Moura, S.J.; Stein, J.L.; Fathy, H.K. Battery-Health Conscious Power Management in Plug-In Hybrid Electric Vehicles via Electrochemical Modeling and Stochastic Control. IEEE Trans. Control Syst. Technol. 2013, 21, 679-694. [CrossRef]

3. Suri, G.; Onori, S. A control-oriented cycle-life model for hybrid electric vehicle lithium-ion batteries. Energy 2016, 96, 644-653. [CrossRef]

4. Guzzella, L.; Sciarretta, A. Vehicle Propulsion Systems, 3rd ed.; Springer: Berlin/Heidelberg, Germany, 2013.

5. Williamson, S.S. Energy Management Strategies for Electric and Plug-in Hybrid Electric Vehicles; Springer: New York, NY, USA, 2013. 
6. Kovaltchouk, T.; Multon, B.; Ahmed, H.B.; Aubry, J.; Venet, P. Enhanced Aging Model for Supercapacitors Taking Into Account Power Cycling: Application to the Sizing of an Energy Storage System in a Direct Wave Energy Converter. IEEE Trans. Ind. Appl. 2015, 51, 2405-2414. [CrossRef]

7. Kovaltchouk, T.; Ahmed, H.B.; Multon, B.; Aubry, J.; Venet, P. An aging-aware life cycle cost comparison between supercapacitors and Li-ion batteries to smooth Direct Wave Energy Converter production. In Proceedings of the 2015 IEEE Eindhoven PowerTech, Eindhoven, The Netherlands, 29 June-2 July 2015; pp. 1-6. [CrossRef]

8. Hammar, A.; Venet, P.; Lallemand, R.; Coquery, G.; Rojat, G. Study of Accelerated Aging of Supercapacitors for Transport Applications. IEEE Trans. Ind. Electron. 2010, 57, 3972-3979. [CrossRef]

9. Zhang, L.; Hu, X.; Wang, Z.; Sun, F.; Deng, J.; Dorrell, D.G. Multiobjective Optimal Sizing of Hybrid Energy Storage System for Electric Vehicles. IEEE Trans. Veh. Technol. 2018, 67, 1027-1035. [CrossRef]

10. Song, Z.; Zhang, X.; Li, J.; Hofmann, H.; Ouyang, M.; Du, J. Component sizing optimization of plug-in hybrid electric vehicles with the hybrid energy storage system. Energy 2018, 144, 393-403. [CrossRef]

11. Eldeeb, H.H.; Elsayed, A.T.; Lashway, C.R.; Mohammed, O. Hybrid Energy Storage Sizing and Power Splitting Optimization for Plug-In Electric Vehicles. IEEE Trans. Ind. Appl. 2019, 55, 2252-2262. [CrossRef]

12. Song, Z.; Li, J.; Hou, J.; Hofmann, H.; Ouyang, M.; Du, J. The battery-supercapacitor hybrid energy storage system in electric vehicle applications: A case study. Energy 2018, 154, 433-441. [CrossRef]

13. Wieczorek, M.; Lewandowski, M. A mathematical representation of an energy management strategy for hybrid energy storage system in electric vehicle and real time optimization using a genetic algorithm. Appl. Energy 2017, 192, 222-233. [CrossRef]

14. Wang, Y.; Wang, L.; Li, M.; Chen, Z. A review of key issues for control and management in battery and ultra-capacitor hybrid energy storage systems. eTransportation 2020, 4, 100064. [CrossRef]

15. Song, Z.; Li, J.; Han, X.; Xu, L.; Lu, L.; Ouyang, M.; Hofmann, H. Multi-objective optimization of a semi-active battery/supercapacitor energy storage system for electric vehicles. Appl. Energy 2014, 135, 212-224. [CrossRef]

16. Shen, J.; Dusmez, S.; Khaligh, A. Optimization of Sizing and Battery Cycle Life in Battery/Ultracapacitor Hybrid Energy Storage Systems for Electric Vehicle Applications. IEEE Trans. Ind. Inform. 2014, 10, 2112-2121. [CrossRef]

17. Akar, F.; Tavlasoglu, Y.; Vural, B. An Energy Management Strategy for a Concept Battery/Ultracapacitor Electric Vehicle With Improved Battery Life. IEEE Trans. Transp. Electrif. 2017, 3, 191-200. [CrossRef]

18. Carter, R.; Cruden, A.; Hall, P.J. Optimizing for Efficiency or Battery Life in a Battery/Supercapacitor Electric Vehicle. IEEE Trans. Veh. Technol. 2012, 61, 1526-1533. [CrossRef]

19. Zhao, C.; Yin, H.; Ma, C. Quantitative Evaluation of LiFePO Battery Cycle Life Improvement Using Ultracapacitors. IEEE Trans. Power Electron. 2016, 31, 3989-3993. [CrossRef]

20. Du, J.; Zhang, X.; Wang, T.; Song, Z.; Yang, X.; Wang, H.; Ouyang, M.; Wu, X. Battery degradation minimization oriented energy management strategy for plug-in hybrid electric bus with multi-energy storage system. Energy 2018, 165, 153-163. [CrossRef]

21. Hou, J.; Song, Z. A hierarchical energy management strategy for hybrid energy storage via vehicle-to-cloud connectivity. Appl. Energy 2020, 257, 113900. [CrossRef]

22. Zhang, S.; Hu, X.; Xie, S.; Song, Z.; Hu, L.; Hou, C. Adaptively coordinated optimization of battery aging and energy management in plug-in hybrid electric buses. Appl. Energy 2019, 256, 113891. [CrossRef]

23. Cordoba-Arenas, A.; Onori, S.; Guezennec, Y.; Rizzoni, G. Capacity and power fade cycle-life model for plug-in hybrid electric vehicle lithium-ion battery cells containing blended spinel and layered-oxide positive electrodes. J. Power Sources 2015, 278, 473-483. [CrossRef]

24. Tang, L.; Rizzoni, G. Energy management strategy including battery life optimization for a HEV with a CVT. In Proceedings of the 2016 IEEE Transportation Electrification Conference and Expo, Asia-Pacific (ITEC Asia-Pacific), Busan, Korea, 1-4 June 2016; pp. 549-554.

25. Mohan, G.; Assadian, F.; Longo, S. Comparative analysis of forward-facing models vs backwardfacing models in powertrain component sizing. In Proceedings of the IET Hybrid and Electric Vehicles Conference 2013 (HEVC 2013), London, UK, 6-7 November 2013; pp. 1-6. [CrossRef]

26. Zeng, X.; Yang, N.; Wang, J.; Song, D.; Zhang, N.; Shang, M.; Liu, J. Predictive-model-based dynamic coordination control strategy for power-split hybrid electric bus. Mech. Syst. Signal Process. 2015, 60-61, 785-798. [CrossRef]

27. Sangtarash, F.; Esfahanian, V.; Nehzati, H.; Haddadi, S.; Bavanpour, M.A.; Haghpanah, B. Effect of Different Regenerative Braking Strategies on Braking Performance and Fuel Economy in a Hybrid Electric Bus Employing CRUISE Vehicle Simulation. SAE Int. J. Fuels Lubr. 2008, 1, 828-837. [CrossRef]

28. Wang, B.H.; Luo, Y.G.; Zhang, J.W. Simulation of city bus performance based on actual urban driving cycle in China. Int. J. Automot. Technol. 2008, 9, 501-507. [CrossRef]

29. Markel, T.; Brooker, A.; Hendricks, T.; Johnson, V.; Kelly, K.; Kramer, B.; O’Keefe, M.; Sprik, S.; Wipke, K. ADVISOR: A systems analysis tool for advanced vehicle modeling. J. Power Sources 2002, 110, 255-266. [CrossRef]

30. Erdinc, O.; Vural, B.; Uzunoglu, M. A dynamic lithium-ion battery model considering the effects of temperature and capacity fading. In Proceedings of the 2009 International Conference on Clean Electrical Power, Capri, Italy, 9-11 June 2009; pp. 383-386.

31. Nelson, R.F. Power requirements for batteries in hybrid electric vehicles. J. Power Sources 2000, 91, 2-26. [CrossRef]

32. Fauvel, C..; Vikesh, N.; Aymeric, R. Medium and Heavy Duty Hybrid Electric Vehicle Sizing to Maximize Fuel Consumption Displacement on Real World Drive Cycles; Power (W): Los Angeles , CA, USA, 2012. 
33. Dougal, R.; Gao, L.; Liu, S. Ultracapacitor model with automatic order selection and capacity scaling for dynamic system simulation. J. Power Sources 2004, 126, 250-257. [CrossRef]

34. Omar, N.; Monem, M.A.; Firouz, Y.; Salminen, J.; Smekens, J.; Hegazy, O.; Gaulous, H.; Mulder, G.; Van den Bossche, P.; Coosemans, T; et al. Lithium iron phosphate based battery-Assessment of the aging parameters and development of cycle life model. Appl. Energy 2014, 113, 1575-1585. [CrossRef]

35. Safari, M.; Morcrette, M.; Teyssot, A.; Delacourt, C. Life-Prediction Methods for Lithium-Ion Batteries Derived from a Fatigue Approach I. Introduction: Capacity-Loss Prediction Based on Damage Accumulation. J. Electrochem. Soc. 2010, 157, A713-A720. [CrossRef]

36. Zhou, C.; Qian, K.; Allan, M.; Zhou, W. Modeling of the Cost of EV Battery Wear Due to V2G Application in Power Systems. IEEE Trans. Energy Convers. 2011, 26, 1041-1050. [CrossRef]

37. Mallon, K.R.; Assadian, F.; Fu, B. Analysis of On-Board Photovoltaics for a Battery Electric Bus and Their Impact on Battery Lifespan. Energies 2017, 10, 943. [CrossRef]

38. Xu, B.; Oudalov, A.; Ulbig, A.; Andersson, G.; Kirschen, D.S. Modeling of lithium-ion battery degradation for cell life assessment. IEEE Trans. Smart Grid 2016, 9, 1131-1140. [CrossRef]

39. Lee, D.H.; Kim, U.S.; Shin, C.B.; Lee, B.H.; Kim, B.W.; Kim, Y.H. Modelling of the thermal behaviour of an ultracapacitor for a 42-V automotive electrical system. J. Power Sources 2008, 175, 664-668. [CrossRef]

40. Mallon, K.; Assadian, F. Robustification and its Implication for Hybrid Electric Vehicle Energy Management Strategies. J. Dyn. Syst. Control. 2020, 143, 091001. [CrossRef]

41. Tate, E.D.; Grizzle, J.W.; Peng, H. Shortest path stochastic control for hybrid electric vehicles. Int. J. Robust Nonlinear Control 2008, 18, 1409-1429. [CrossRef]

42. Lin, C.C.; Peng, H.; Grizzle, J.W. A stochastic control strategy for hybrid electric vehicles. In Proceedings of the 2004 American Control Conference, Boston, MA, USA, 30 June-2 July 2004; Volume 5, pp. 4710-4715.

43. Johannesson, L.; Asbogard, M.; Egardt, B. Assessing the Potential of Predictive Control for Hybrid Vehicle Powertrains Using Stochastic Dynamic Programming. IEEE Trans. Intell. Transp. Syst. 2007, 8, 71-83. [CrossRef]

44. Vagg, C.; Akehurst, S.; Brace, C.J.; Ash, L. Stochastic dynamic programming in the real-world control of hybrid electric vehicles. IEEE Trans. Control Syst. Technol. 2015, 24, 853-866. [CrossRef]

45. Opila, D.F.; Wang, X.; McGee, R.; Grizzle, J. Real-time implementation and hardware testing of a hybrid vehicle energy management controller based on stochastic dynamic programming. J. Dyn. Syst. Meas. Control 2013, 135, 021002. [CrossRef]

46. Zhu, T.; Wills, R.G.A.; Lot, R.; Kong, X.; Yan, X. Optimal sizing and sensitivity analysis of a battery-supercapacitor energy storage system for electric vehicles. Energy 2021, 221, 119851. [CrossRef]

47. US Energy Information Administration. July 2021 Monthly Energy Review; Technical Report; U.S. Energy Information Administration: Washington, DC, USA, 2021.

48. Barlow, T.J.; Latham, S.; Mccrae, I.S.; Boulter, P.G. A Reference Book of Driving Cycles for Use in the Measurement of Road Vehicle Emissions; TRL Published Project Report; Transport Research Laboratory: Crothorne, UK, 2009.

49. Hughes-Cromwick, M. 2019 Public Transportation Fact Book; World Transit Research; American Public Transportation Association: Chicago, IL, USA, 2019.

50. Min, H.; Lai, C.; Yu, Y.; Zhu, T.; Zhang, C. Comparison Study of Two Semi-Active Hybrid Energy Storage Systems for Hybrid Electric Vehicle Applications and Their Experimental Validation. Energies 2017, 10, 279. [CrossRef]

51. Mongird, K.; Viswanathan, V.V.; Balducci, P.J.; Alam, M.J.E.; Fotedar, V.; Koritarov, V.S.; Hadjerioua, B. Energy Storage Technology and Cost Characterization Report; Technical Report; Pacific Northwest National Lab. (PNNL): Richland, WA, USA, 2019.

52. Wang, J.; Liu, P.; Hicks-Garner, J.; Sherman, E.; Soukiazian, S.; Verbrugge, M.; Tataria, H.; Musser, J.; Finamore, P. Cycle-life model for graphite- $\mathrm{LiFePO}_{4}$ cells. J. Power Sources 2011, 196, 3942-3948. [CrossRef]

53. Serrao, L.; Onori, S.; Sciarretta, A.; Guezennec, Y.; Rizzoni, G. Optimal energy management of hybrid electric vehicles including battery aging. In Proceedings of the 2011 American Control Conference, San Francisco, CA, USA, 29 June-1 July 2011; pp. 2125-2130. [CrossRef]

54. Lin, X.; Hao, X.; Liu, Z.; Jia, W. Health conscious fast charging of Li-ion batteries via a single particle model with aging mechanisms. J. Power Sources 2018, 400, 305-316. [CrossRef]

55. Laver, R.; Schneck, D.; Skorupski, D.; Brady, S.; Cham, L. Useful Life of Transit Buses and Vans; Number: FTA-VA-26-7229-07.1; National Academy of Sciences: Washington, DC, USA, 2007. 